\title{
Polyoptimisation of the Aerodynamic and Aeroacoustic Performance of Aerofoils with Serrated Leading Edges
}

\author{
Till M. Biedermann ${ }^{1}$, Frank Kameier ${ }^{2}$, Oliver Koster ${ }^{3}$, Denis Schreiber ${ }^{4}$ \\ Duesseldorf University of Applied Sciences, Duesseldorf, D-40476, Germany \\ Tze Pei Chong 5 \\ Brunel University London, London, UB83PH, UK \\ and \\ Christian O. Paschereit ${ }^{6}$ \\ Berlin Technical University, Berlin, D-10623, Germany
}

\begin{abstract}
Recent research confirmed leading edge serrations to be an effective passive noise reduction treatment for aerofoil broadband noise at high-turbulent inflow conditions. Therefore, reducing leading edge broadband noise while maintaining acceptable aerodynamic aerofoil performance represents a pressing task for future applications. In this context, an extensive aeroacoustic study, analysing a NACA65(12)-10 aerofoil, was continued towards defining an aeroacoustic optimum between aerofoil noise radiation and noise reduction due to serrated leading edges in order to provide ideal design parameters for low-noise serrations. On this basis, part of the aeroacoustically analysed experimental space was extracted and analysed in terms of aerodynamic performance parameters, defined by lift and drag coefficients. This was carried out both, numerically and experimentally. The main parameters of interest were a variation of the Reynolds number, the angle of attack and the serration design parameters, namely the serration amplitude and the serration wavelength. The aerodynamic study showed a good match between experimental and numerical results in the pre-stall regime. Slight deviations occurred in a precise determination of the stall-angle and the maximum lift coefficients which mainly could be assigned to differing boundary conditions. However, for the serrations slight improvements of the maximum pre-stall angles as well as high post-stall lift coefficients were observed, which could be linked to specific separation pattern on the aerofoil suction side. An increase of the serration wavelength showed an increased lift performance, which could not be linked solely to a change in the aerofoils surface. Combining aeroacoustic and aerodynamic results showed that the aerodynamic trends towards a maximum lift performance compete aeroacoustic maximum-performance findings. Finally, defining a polyoptimum of the multi-parameter system in terms of maximum noise reduction effects while maintaining an acceptable aerodynamic performance provides a deepened insight into the relations between aerodynamics and aeroacoustics, where the presented data pool might give assistance for future design processes.
\end{abstract}

\footnotetext{
${ }^{1}$ Doctoral Researcher, Institute of Sound and Vibration Engineering ISAVE, till.biedermann@hs-duesseldorf.de, AIAA Student Member.

${ }^{2}$ Professor, Institute of Sound and Vibration Engineering ISAVE, frank.kameier@hs-duesseldorf.de.

${ }^{3}$ M.Sc. Student, Institute of Sound and Vibration Engineering ISAVE, oliver.koster@fh-duesseldorf.de.

${ }^{4}$ M.Sc. Student, Institute of Sound and Vibration Engineering ISAVE, denis.schreiber@fh-duesseldorf.de.

${ }^{5}$ Senior Lecturer, Department of Mechanical, Aerospace and Civil Eng., t.p.chong@brunel.ac.uk, AIAA Member.

${ }^{6}$ Professor, Institute of Fluid Dynamics and Technical Acoustics ISTA, oliver.paschereit@tu-berlin.de.
}

American Institute of Aeronautics and Astronautics 


\section{Nomenclature}

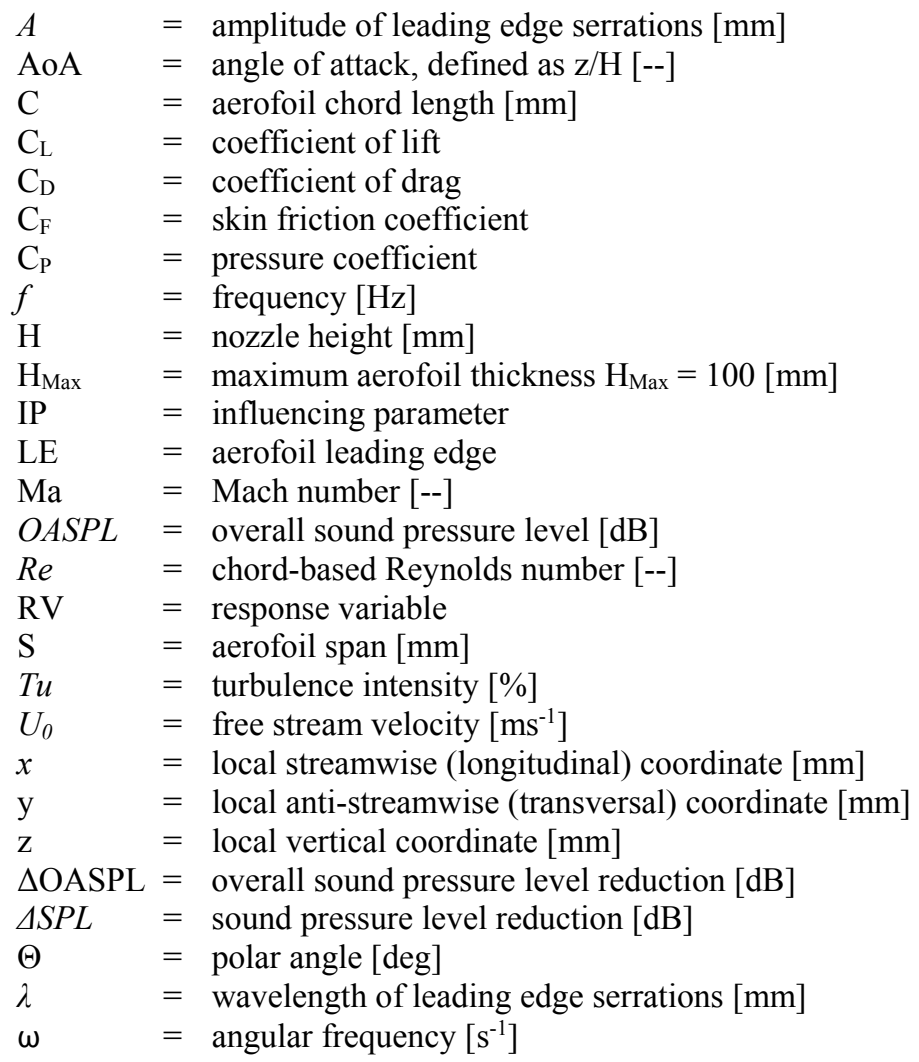

\section{Introduction}

ERRATED leading edges are known for their beneficial aerodynamic and aeroacoustic effects. They increase $\checkmark$ the maximum pre-stall angle and help achieving high post-stall lift coefficients, also reducing leading edge broadband noise at high-turbulent inflow conditions and suppressing the feedback loop at aerofoil trailing edges in laminar flows. However, recent scientific studies mostly focussed on analysing aerodynamic or aeroacoustic effects separately ${ }^{1-11}$. This pushes the question forward on how aeroacoustically optimised serrations should be designed while maintaining a feasible aerodynamic performance.

With the objective of reducing the broadband noise emitted from the interaction of highly turbulent flows and aerofoil leading edges, sinusoidal leading edge serrations (LE Serrations) were already investigated as an effective passive treatment in $2016^{12 ; 13}$ and $2017^{14}$. An extensive aeroacoustic study was performed in order to determine the main influences and interdependencies of factors, such as the Reynolds number, turbulence intensity, serration amplitude and wavelength as well as the angle of attack on the noise reduction capability (Table 1). A statisticalempirical model was developed to predict the overall sound pressure level and noise reduction of a NACA65(12)-10 aerofoil with and without leading edge serrations in the range of chord-based Reynolds numbers of $2.5 \cdot 10^{5} \leq \operatorname{Re} \leq$ $6 \cdot 10^{5}$ and a geometrical angle of attack $-10 \mathrm{deg} \leq \alpha \leq+10 \mathrm{deg}$ (Eq. 1). The observed main influencing factors match current research results to a high degree and were quantified in a systematic order for the first time. Moreover, significant interdependencies of the turbulence intensity and the serration wavelength, as well as the serration wavelength and the angle of attack were observed, validated and quantified. The statistical-empirical model was validated against an external set of experimental data, which has shown to be accurate and reliable. Corresponding to the aeroacoustic study, PIV experiments were conducted in order to visualise the flow pattern at characteristic experimental settings and to draw conclusions regarding the relationship between noise reduction mechanisms and the flow structures.

$$
R V_{i}=f\left\{\sum_{j=1}^{n}\left(\left(I P_{j}+I P_{j}^{2}\right)+\sum_{k=1}^{n}\left(I P_{j} I P_{j+k}\right)\right)\right\}\left\{\begin{array}{l}
i=1 . .4 \\
j=1 . .5 \\
k=1 . .4
\end{array}\right.
$$


Table 1, Analysed aeroacoustic parameters ${ }^{13}$.

\begin{tabular}{|c|c|c|c|c|c|c|}
\hline & Unit & $\operatorname{Min}(-\alpha)$ & $-1 \mathrm{DoE}$ & ODoE & $+1_{\mathrm{DoE}}$ & $\operatorname{Max}(+\alpha)$ \\
\hline $\boldsymbol{x}_{\text {Nondim }}$ & -- & -2.378 & -1.0 & 0.0 & +1.0 & +2.378 \\
\hline$R e$ & -- & 250,000 & 351,422 & 425,000 & 498,578 & 600,000 \\
\hline$T u(u)$ & $\%$ & 2.08 & 3.07 & 3.79 & 4.51 & 5.50 \\
\hline$A_{\text {Serr }} / C$ & -- & 0.080 & 0.144 & 0.190 & 0.236 & 0.300 \\
\hline$\lambda_{\text {Serr }} / C$ & -- & 0.050 & 0.122 & 0.175 & 0.228 & 0.300 \\
\hline$z / H$ & -- & -0.128 & -0.054 & 0.000 & 0.054 & 0.128 \\
\hline
\end{tabular}

Leading edge serrations are expected to represent an effective passive noise reduction treatment for e.g. stator vanes of axial fans. In order to create a meaningful similarity for future applications, a cambered NACA65(12)-10 (Fig. 1), which is a commonly used profile for stator vanes, was analysed. The presented work here takes up the aeroacoustic study by Biedermann et al. in 2016, where the analysed multi-parameter space provided a metamodel for noise radiation and noise reduction as a function of five parameters ${ }^{13}$. In Section II, this study is extended towards the definition of optimum design parameters for low noise radiation and a maximum noise reduction due to serrated leading edges. The aeroacoustically analysed data is processed in terms of aerodynamics according to the Design of Experiments (DoE) methodology by applying both, numerical and experimental approaches (Section III). Main parameters of interest were the Reynolds number, the angle of attack and serration design parameters, namely the serration wavelength and the serration amplitude. Aerodynamic results as well as a comparison of numerical and experimental results are presented in Section IV, including a detailed analysis of the separation process for the serrations and an evaluation of the local pressure distribution along the aerofoil chord. Moreover, the numerical approach enables a comparison to previously conducted PIV flow pattern visualisations. Finally, Section V combines aeroacoustic and aerodynamic results at similar settings of the influencing parameters. The aim is to gather interrelated information on aeroacoustics and aerodynamic performance in order to make the next step towards practical application.
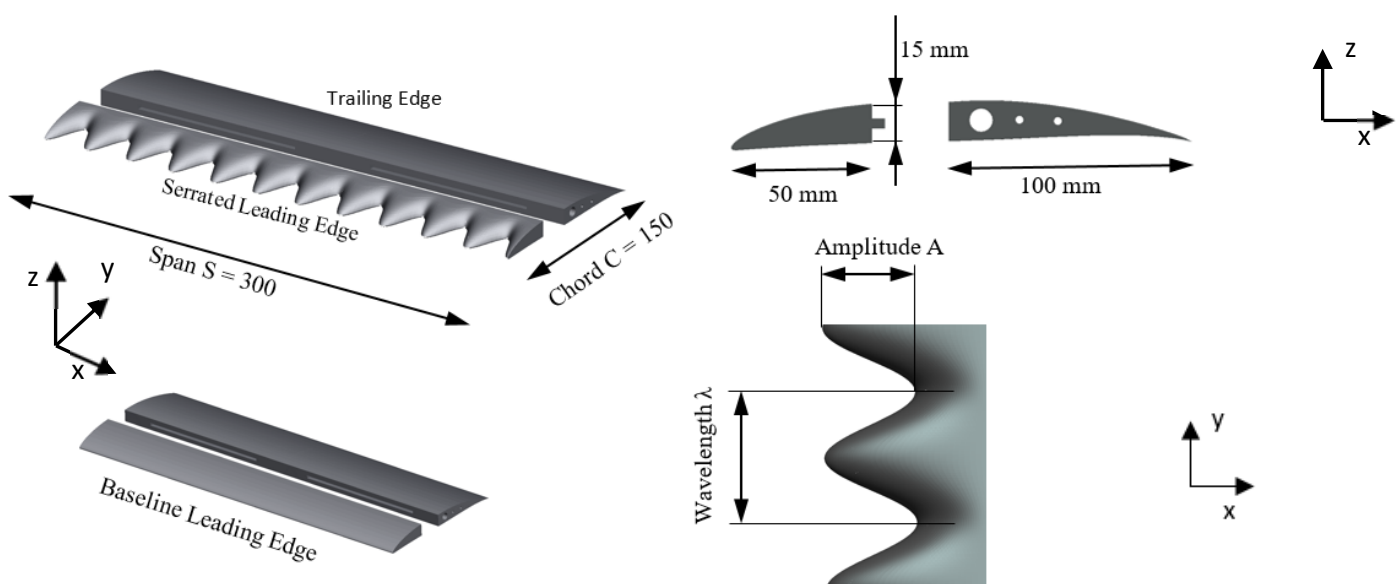

Fig.1, NACA65(12)-10 aerofoil main body and re-attachable leading edge with measures of importance for the acoustical treatment in the open jet stream.

\section{Preliminary Acoustics}

\section{A. Aeroacoustic Results}

The aeroacoustic measurements resulted in a clear ranking and quantification of the influencing parameters, where the Reynolds number $(\mathrm{Re})$ and the freestream turbulence intensity $(\mathrm{Tu})$ are the main contributors to broadband noise emissions. The serration amplitude $(\mathrm{A} / \mathrm{C})$, followed by the Reynolds number and the serration wavelength $(\lambda / \mathrm{C})$ represents the main factor for an effective broadband noise reduction. The aeroacoustic trends of $\mathrm{A} / \mathrm{C}$ and $\lambda / \mathrm{C}$ are shown in Fig. 2. A significant interdependency of the serration wavelength and the freestream turbulence intensity $(\lambda / \mathrm{C} \cdot \mathrm{Tu})$ with regard to the overall noise reduction capability was identified. This feature could be linked to the characteristic size of the incoming gust relative to the size of the serration wavelength. For low turbulence intensities, small wavelengths result in maximum noise reduction whereas for high $\mathrm{Tu}$ intermediate wavelengths are more

American Institute of Aeronautics and Astronautics 
beneficial. Another finding was an interdependency of the angle of attack and the serration wavelength $(\mathrm{z} / \mathrm{H} \cdot \lambda / \mathrm{C})$ with regard to the overall noise reduction capability. This characteristic behaviour could be assigned to three-dimensional effects when the flow is approaching the aerofoil, meaning a preference of large serration wavelengths at high positive angles of attack where at negative angles low serration wavelengths are sufficient to provide a smooth flow along the serrated section. Moreover, the mechanism that causes an increased level of self-noise radiation (high-frequency noise) was identified to be due to the presence of small serration wavelengths, which facilitate cross-flow from the projected upper surface of the LE, through the serration air gaps and exits the lower surface of the LE. This particular fluidstructure interaction causes the noise to increase at high frequency that will otherwise be absent in a baseline LE ${ }^{14}$.

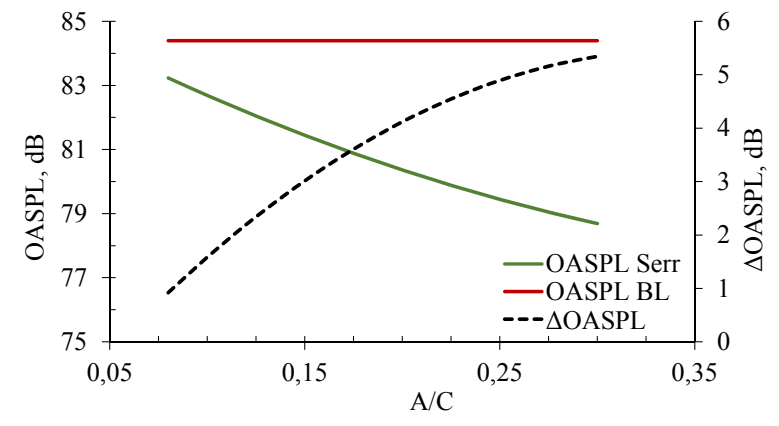

a)

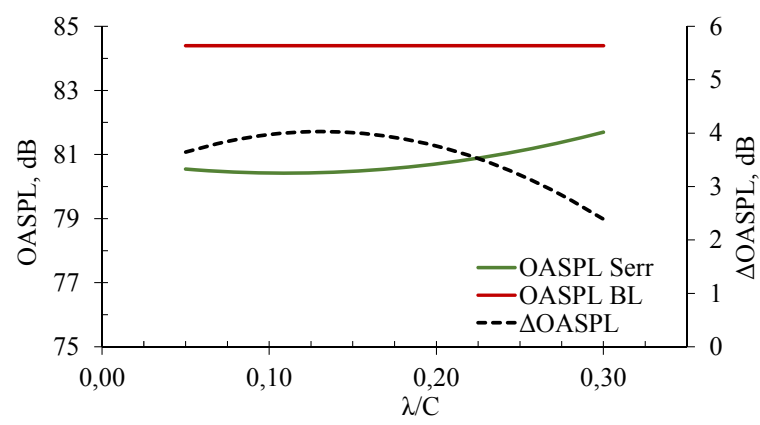

b)

Fig.2, Intermediate influence of the analysed factors on the response variables. Disregarded influencing factors remain on intermediate levels $(\operatorname{Re}=425,000, T u=3.8 \%, A / C=0.19, \lambda / C=0.175, z / H=0)$. a) Influence of normalised serration amplitude $(\mathrm{A} / \mathrm{C})$; b) Influence of normalised serration wavelength $(\lambda / \mathrm{C})$.

\section{B. Optimum of Noise Radiation and Noise Reduction}

The purpose of the analysed system is to reduce the broadband leading edge noise caused by the interaction between the high turbulent inflow and the leading edge. Therefore, in addition to aiming to achieve a high noise reduction by comparing aerofoils with straight and serrated leading edges, a low absolute magnitude of the overall sound pressure is also desirable. The established algorithm has been used to define an optimum of the radiated noise and the noise reduction capability by use of the serrated leading edges. Of further interest are qualitative information with regard to the impact of the different analysed parameters on the optimum. As stated by Eq. 2, the independent response variables OASPL Serr $_{\text {and }}$ OASPL are weighted with an emphasis on a reduction of the OASPL. This means that the OASPL is weighted linearly between $50-70 \mathrm{~dB}$ where $50 \mathrm{~dB}$ equals an acceptability of $100 \%$. In contrast, the $\triangle \mathrm{OASPL}$ is weighted by a quadratic function which accounts for zero percent acceptability at $2 \mathrm{~dB}$ with a rising slope towards high noise reduction levels until reaching the desired optimum of $10 \mathrm{~dB}$ overall noise reduction $(Z=1$ or $100 \%$ acceptability, respectively). According to Eq. 3, the response variables OASPL $L_{\text {Serr }}$ and $\triangle$ OASPL are maximised in the given parameter range. Alternatively, an unweighted optimum can be achieved by determining a pareto front (pareto optimal solutions) as described by Reich et al. ${ }^{15}$, where non-dominated solutions are expressed as a function, covering the multi-dimensional optimum in the experimental space.

$$
\begin{aligned}
& \bar{Z}=1 / 2\left(\frac{O A S P L_{S e r r}-70}{-20}+\frac{1}{30}(\sqrt{120 \cdot \Delta O A S P L-239}-1)\right) \\
& R e \in[2.5 E 5,6 E 5] \\
& T u \in[2.1,5.5] \\
& A / C \in[0.08,0.3] \\
& \max _{\bar{Z} \in[0 . .1]} \bar{Z}\left(\operatorname{Re}, T u, \frac{A}{C}, \frac{\lambda}{C}, \frac{z}{H}\right) \in[0.05,0.3] \\
& z / H \in[-0.128,0.128]
\end{aligned}
$$

Figure 3 shows the optimum of noise radiation and noise reduction with serrated LE. The first row indicates the dependencies on the noise radiation where the Reynolds number retains the main impact, followed by turbulence intensity and serration amplitude. The serration wavelength and angle of attack, on the other hand, only exhibit secondary importance. A similar trend can be seen for the noise reduction as illustrated in the second row in Fig. 3, albeit the effect of serration amplitude is superimposing the effect of the Reynolds number. The serration wavelength and the angle of attack play less important roles in terms of noise reduction. 
A maximum noise reduction of $\triangle \mathrm{OASPL}=7.5 \mathrm{~dB}$, while maintaining a relatively low noise radiation of $\mathrm{OASPL}=$ $53.8 \mathrm{~dB}$, is reached at minimum Reynolds number, turbulence intensity and serration wavelength in combination with maximum serration amplitude and a high angle of attack. As the third row shows, the contribution of single parameters to the optimum, indicated as acceptability, spreads over large margins. In order to achieve a minimum noise radiation while maintaining a high noise reduction capability of the serrations, one could utilize the algorithm of the optimum to optimise the effective degrees of freedom when other design parameters are fixed.
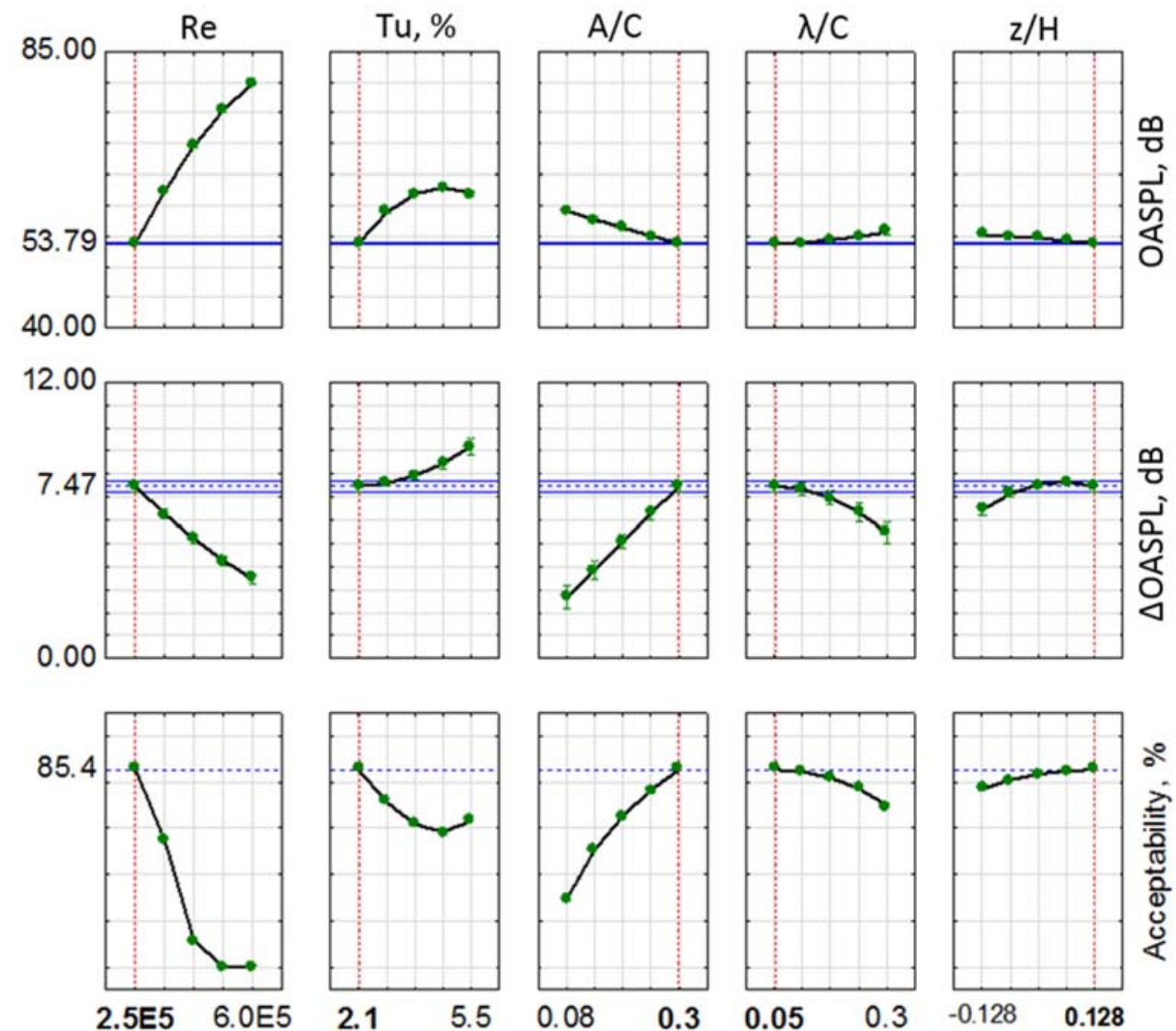

Fig.3, Optimum of the OASPL (top) and the noise reduction capability $\triangle$ OASPL (centre), defined by functions of acceptability (Eq. 2). Additional plot of the effect of influencing parameters on the acceptability (bottom).

\section{Setup Conditions}

The developed model on the aeroacoustic performance of serrated LE in Section II clearly identified, in addition to similar findings by other researchers ${ }^{16-20}$, significant benefits of this application in terms of acoustics. However, LE serrations are also known to have an impact on the aerodynamic characteristics. As previous studies showed, serrations lead to slight decreases in lift while the separation point of the aerofoil is delayed what leads to higher maximum angles of attack in the pre-stall regime. Post-stall, the serrations prevent a sharp decrease of the lift, which occurs in the case of straight leading edges ${ }^{21-23}$. The aim of the current analysis is to supplement the developed aeroacoustic model with information on the aerodynamic performance of the serrations. Hence, a numerical and an experimental study of a cambered NACA65(12)-10 with straight (BSLN) and serrated leading edges was carried out. The incoming flow velocity was set to $\mathrm{U}_{0}=15 \mathrm{~ms}^{-1}$ or $\mathrm{Re}=150,000$, respectively, while the angle of attack ranged between -0.256 $\leq \mathrm{z} / \mathrm{H} \leq 0.256$ or $-20 \mathrm{deg} \leq \alpha \leq 20 \mathrm{deg}$. For the baseline case, the numerical results can be partly compared to the two dimensional Xfoil formulation (pre-stall), based on the inviscid linear-vorticity stream function panel method ${ }^{24}$. Moreover, a comparison to selected experimental results is possible. 


\section{A. Experimental Setup and Measurement Technique}

Aerodynamic force measurements were made in a conventional wind tunnel with closed-working section. This wind tunnel (Fig. 4a) is not acoustically treated and is not suitable for noise measurements. Instead, it is only used for measurements of the lift and drag produced by the aerofoil with sinusoidal leading edges. The wind tunnel has a test section of $0.5 \mathrm{~m} \mathrm{x} 0.5 \mathrm{~m}$, a maximum velocity in the test section of about $\mathrm{U}_{0, \mathrm{Max}}=38 \mathrm{~ms}^{-1}$ and a freestream turbulence intensity of about $\mathrm{Tu}=0.2-0.3 \%{ }^{1}$. The aerofoil model was mounted horizontally across almost the entire width of the test section ( $1 \mathrm{~mm}$ gap on each side of the wind tunnel side window). In order to investigate the effect of the sinusoidal leading edges on the aerodynamic forces, a 3-component strain gauge force balance was used to measure the aerodynamic forces produced by the aerofoil. As shown in Fig. 4b, it consists of a mounting plate, which is used to secure the device to the wind tunnel side window, and a triangular force plate. The force plate and the mounting plate were connected via three spherical universal joints constraining the motion of the force plate parallel to the direction of the mounting plate. Forces incurred by the aerofoil were transmitted to three strain gauges via the cables. The angle of attack of the aerofoil was rotated via a disc between $-20 \mathrm{deg} \leq \mathrm{AoA} \leq 20 \mathrm{deg}$. Wind tunnel blockage correction was applied in the data analysis.

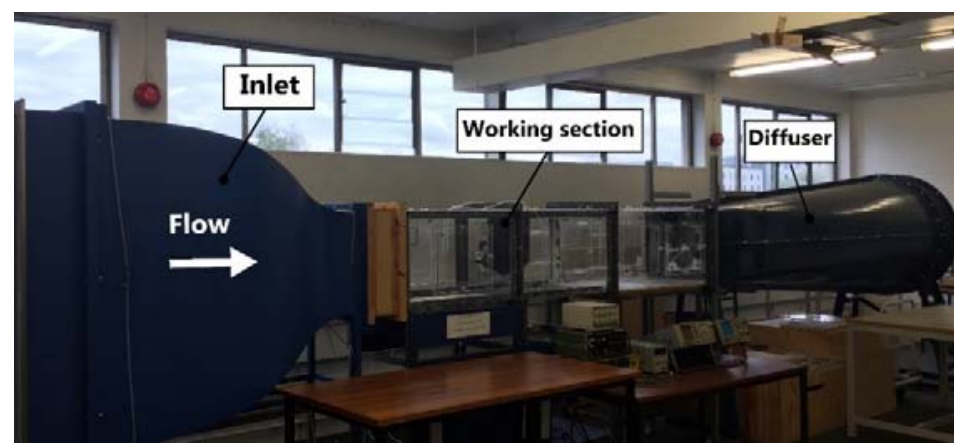

a)

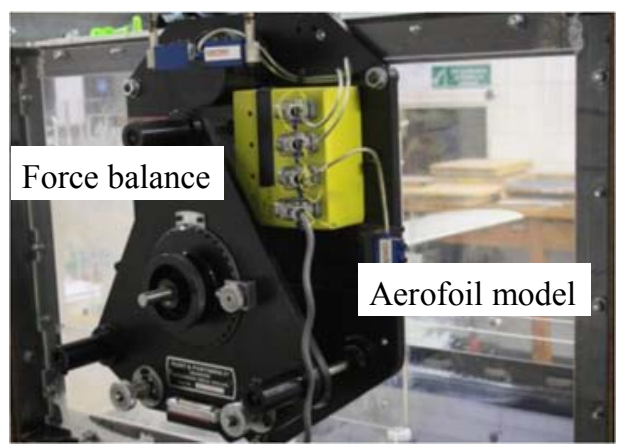

b)

Fig.4, Aerodynamic test facility at Brunel University London. a) Open circuit, suction type wind tunnel. b) 3-component strain gauge force balance used for lift and drag measurements of the aerofoil ${ }^{1}$.

\section{B. Numerical Setup}

The numerical setup consists of solving compressible (U)RANS equations while modelling of the turbulent boundary layer took place by use of the SST turbulence model. In addition, the $\gamma$ - $\operatorname{Re}_{\theta}$-transition model was applied in order to take respect to the transition of the boundary layer from laminar to turbulent. The free stream velocity was defined at the inlet-domain while the modelled turbulence intensity was defined at the inlet as well but with the condition to match the experimental conditions and be $\mathrm{Tu}=5 \%$ at the aerofoil leading edge. The numerical analysis was mainly performed steady state as preliminary simulations showed an extension to a transient problem not to have a significant impact on the lift and drag performance in the pre-stall region. For determining the lift-coefficients in post-stall, however, more detailed transient simulations are necessary and were carried out for exemplary cases.

In terms of meshing, a structured mesh with hexahedrons and cuboids was used (Fig. 5). The dimensions of the meshed domain were set, based on the aerofoil chord, to a multiple of 18 in the streamwise (x-wise) and a multiple of 16 in the anti-streamwise (y-wise) direction. Regarding the aerofoil surface, the chord (x-wise) was meshed with 1170 nodes $/ \mathrm{m}$ and the span (z-wise) with 1560 nodes $/ \mathrm{m}$. Special care was directed towards the resolution of the leading and trailing edge of the aerofoil (Fig. 5b). Starting at the aerofoil surface, an inflation layer was defined by an expansion with a constant ratio of 1.1 while the location of the first layer was set to the non-dimensional value of $0.001<y+<$ 1 in order to guarantee precise resolving of the turbulent boundary layer via the chosen SST turbulence model (Eq. 4), where $\mathrm{u}_{\tau}$ is the friction velocity, $v$ the kinematic viscosity, $\tau_{\mathrm{w}}$ the wall shear stress and $\rho$ the fluid density. The chosen mesh parameters resulted in a total amount of $8 \cdot 10^{6}$ to $16 \cdot 10^{6}$ nodes in the final meshes. Referring to mesh quality criteria, the overall maximum dihedral angle was kept below 160 degrees, the aspect ratio (AR) below 200 and the volume change below 6 . Considerations on the grid quality were supplemented by a grid and domain study in order to prove the independence of the chosen scales.

$$
y^{+}=u_{\tau} \cdot y / v \text { with } u_{\tau}=\left(\tau_{w} / \rho\right)^{1 / 2}
$$



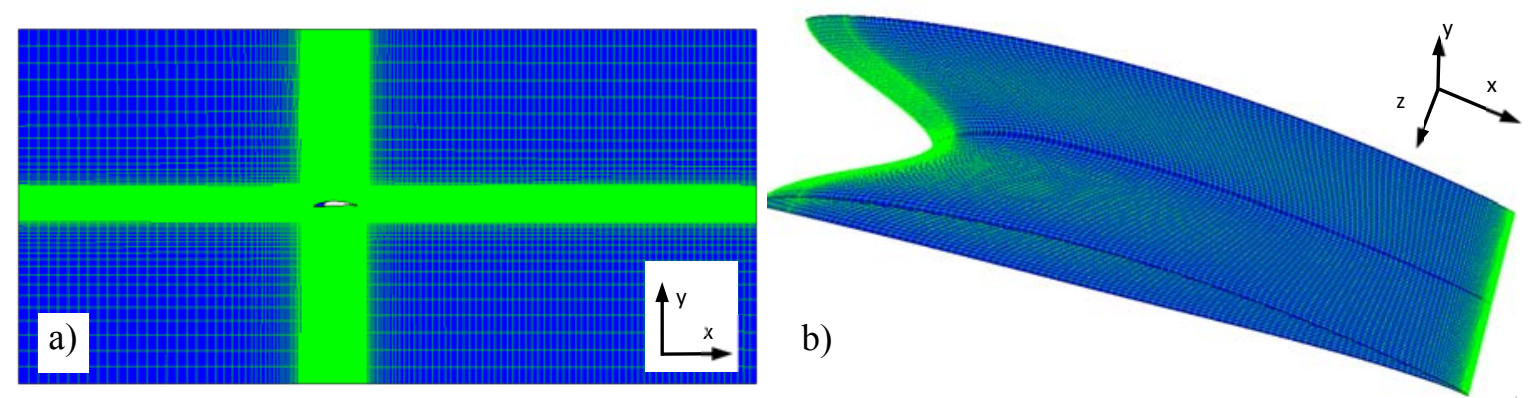

Fig.5, Extraction of the defined mesh for the numerical study. a) Full domain with visible inflation layer and position of analysed aerofoil; b) Surface mesh of serrated (A29 45 ) aerofoil with refinement of LE and TE.

\section{Selected Aerodynamic Results}

\section{A. Lift and Drag Performance}

Aerofoils with a baseline LE as well as five serrated LEs were compared at Re=150,000 in terms of lift and drag coefficients. Assuming the flow is aligned with the x-direction, the coefficients of lift and drag are defined as shown in Eq. 5-6, where A is the effective surface area of the aerofoil. In order to enable a comparison between serrated LEs and the baseline leading edge, this area was defined to be constant as for the baseline case. Thus, for the serrated cases the real effective area is smaller compared to the one chosen for the definition of lift and drag coefficients. Figure 6a shows the lift coefficients for different angles of attack (AoA). The comparison with the two-dimensional Xfoil panel-code exhibits a close fit while a discrepancy to experimental results particularly occurs at high AoA. This could be partly attributed to differences between numerical and experimental setup, namely to a lower experimental Tu, leading to a delayed transition of the boundary layer. Moreover, effects of limiting walls, as it is the case for the experiments, were not considered in the numerical setup. As it is shown in Fig. 14, at high AoA a reattachment of the boundary layer close to the aerofoils trailing edge occurs for the baseline case, leading to higher $\mathrm{C}_{\mathrm{L}}$ than determined

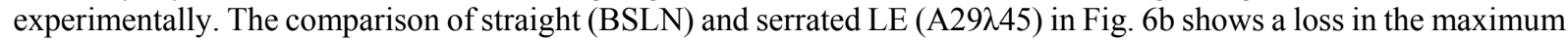
lift of the serrated LE of up to $20 \%$, while the effective surface area decreases by only $6.3 \%$. Thus, the decrease in effective area seems not to be the only cause for the lower lift with serrated LEs at high AoA. This observation is analysed in more detail in Section IV-B and IV-C. In the pre-stall region only minor differences were observed.

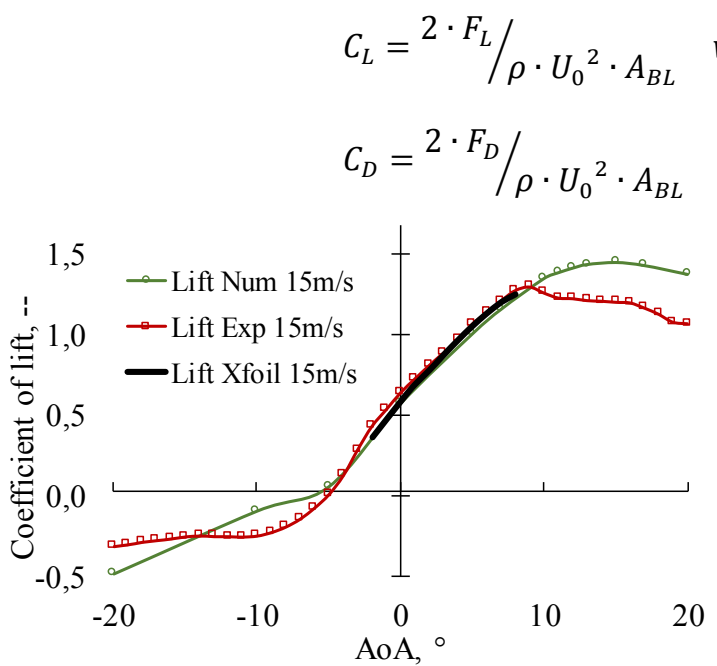

a)

Fig.6, a) Numerical and experimental results of baseline $\mathrm{LE}$ at $\mathrm{Re}=\mathbf{1 5 0 , 0 0 0}$ and $\mathrm{Tu} u \mathrm{Num}=5 \%$. b) Numerical comparison of lift and drag coefficients with varying AoA for baseline and $A 29 \lambda 45$ case at $\operatorname{Re}=150,000$ and

$$
\text { Tunum }=5 \% \text {. }
$$$$
7
$$

American Institute of Aeronautics and Astronautics 
Comparing multiple serrated cases with the baseline (Fig. 7) results in several observations. The post-stall region of the baseline LE is more distinct while there is only a diffuse stall region for the serrated LE. In general, the numerical and the experimental study show a reasonably good fit in the pre-stall region and a comprehensible fit in the post-stall region, when taking respect to the different boundary conditions for the experimental and the numerical approach. As can be seen in Fig. 7, the serration wavelength and amplitude show to have a significant influence on the lift coefficients, especially in the post-stall region, where high serration wavelengths $(\lambda>7.5 \mathrm{~mm})$ and low amplitudes lead to maximum lift performance. This competes the aeroacoustic findings, where maximum amplitudes and minimum to intermediate wavelengths are most beneficial for high noise reduction. Moving the focus to the numerical results in Fig. 8 shows similar findings for the influence of the serration amplitude, but a deviant pattern for the wavelength which shows to have almost no influence on the lift. This leads to the conclusion that for the experimental results, effects such as the influence of surface roughness and cross-flows between small serration gaps play a dominant role with regards to lift performance.

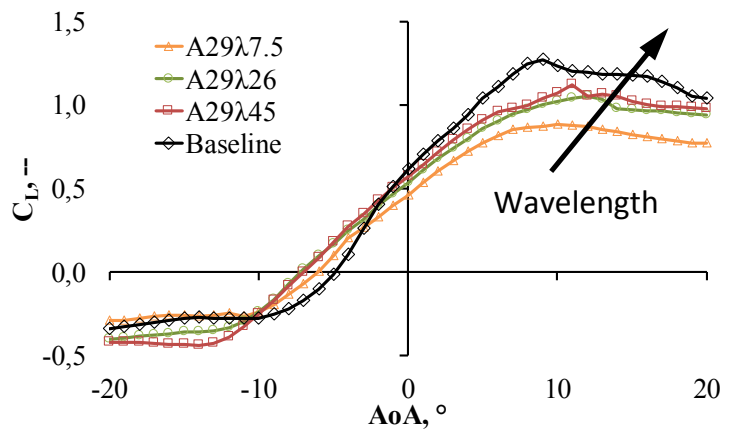

a)

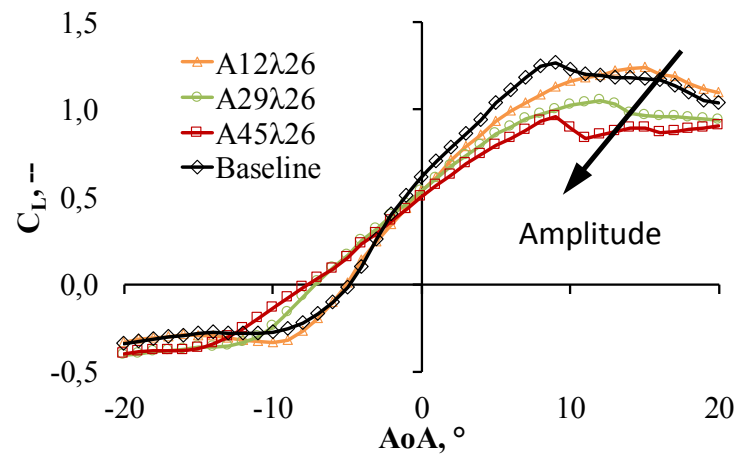

b)

Fig.7, Experimental results of the lift coefficients at $\mathrm{Re}=150,000$. a) Varying serration wavelength; b) Varying serration amplitude.

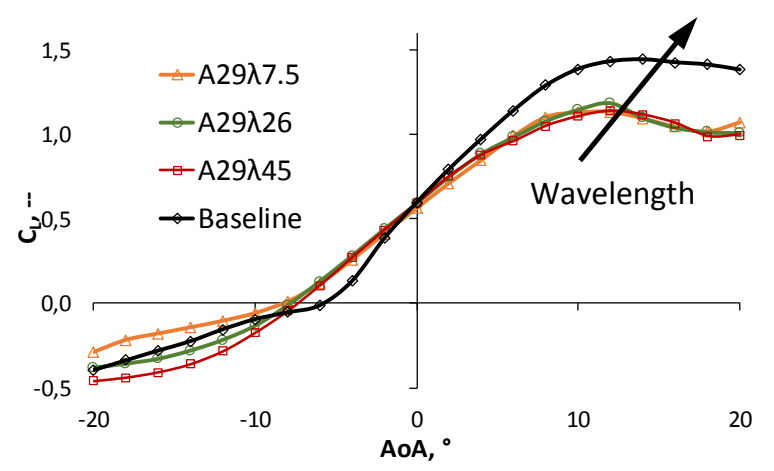

a)

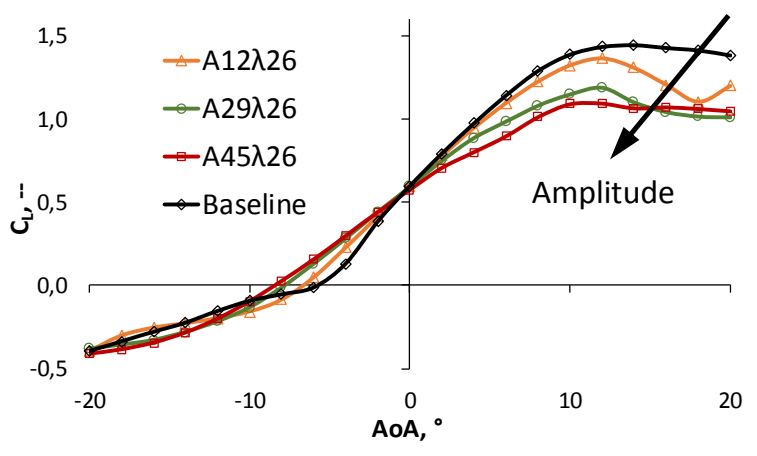

b)

Fig.8, Numerical results of the lift coefficients at $\mathrm{Re}=150,000$. a) Varying serration wavelength; b) Varying serration amplitude.

Figure 9 shows the experimentally obtained lift-to-drag ratio $C_{L} / C_{D}$ as a function of the angle of attack for all analysed serrated leading edges, as well as for the baseline case. As for the lift coefficients, the serration amplitude and wavelength represent the main influencing factors. Herein, the A12 226 shows the best overall performance, even exceeding the BSLN case despite the smaller effective area of the serration. Extracting the factorial core of the analysed serrations (Table 2) and treating it in terms of statistics, a linear dependency between the $\mathrm{C}_{\mathrm{L}} / \mathrm{C}_{\mathrm{D}}$ ratio and the serration parameters could be identified (Fig. 10), confirming high serration wavelengths and small amplitudes to be the parameters of choice for maximum aerodynamic performance. 
Both, the numerical and the experimental study confirm the serration amplitude to affect the lift and drag performance to a high degree where small amplitudes lead to a maximum in lift. This can be assigned to changes in the aerofoil surface and altered flow patterns.

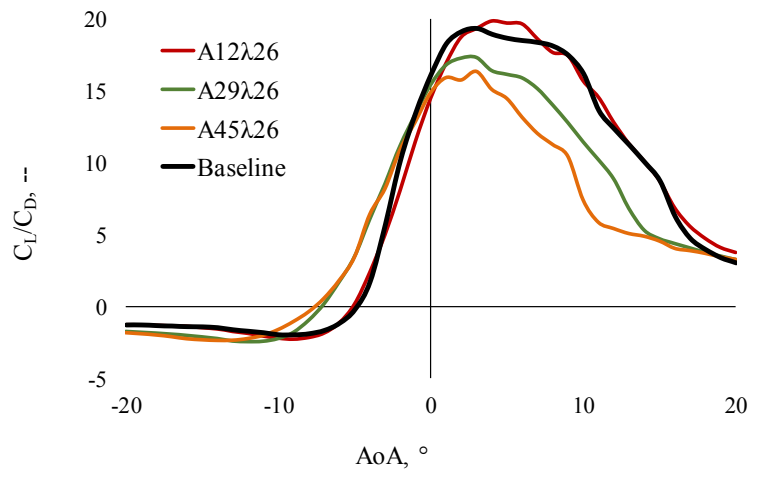

a)

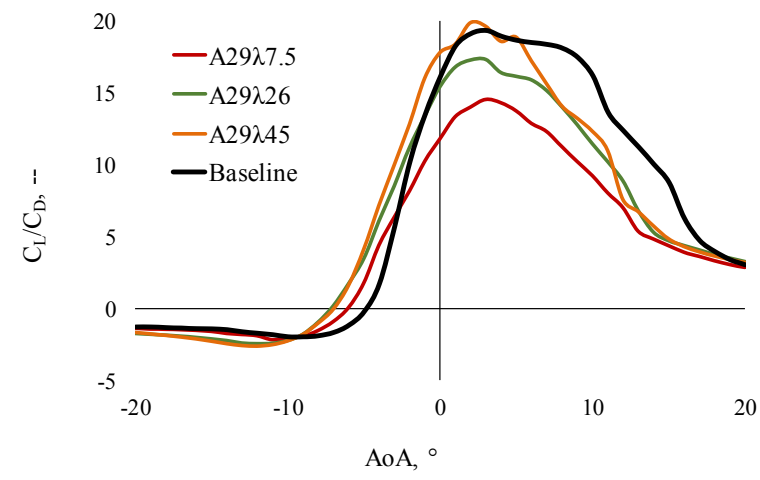

b)

Fig.9, Experimentally obtained lift-to-drag ratio of different LE serrations, characterised by serration amplitude (A) and serration wavelength ( $\lambda$ ). Additional plot of the baseline case (straight LE). a) Varying serration amplitude; b) Varying serration wavelength.
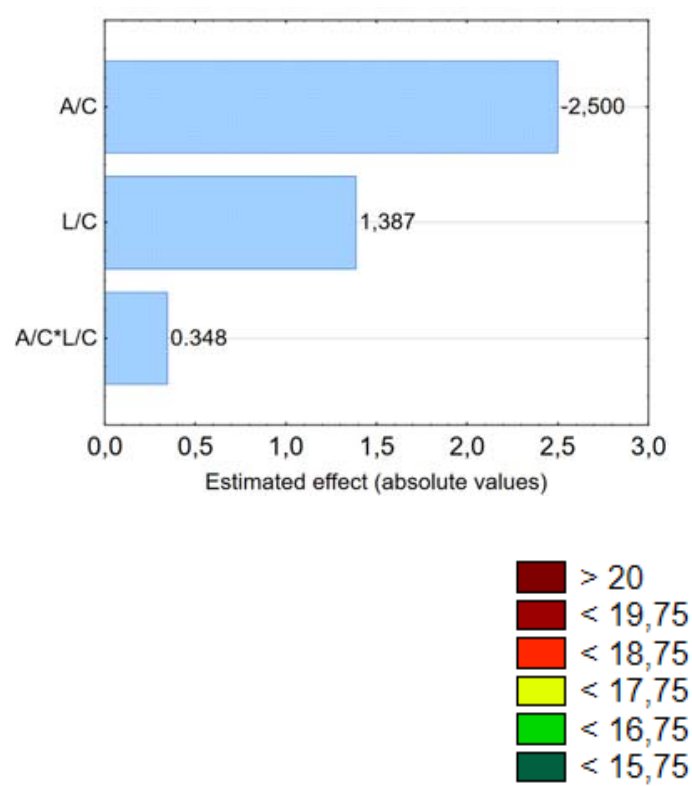

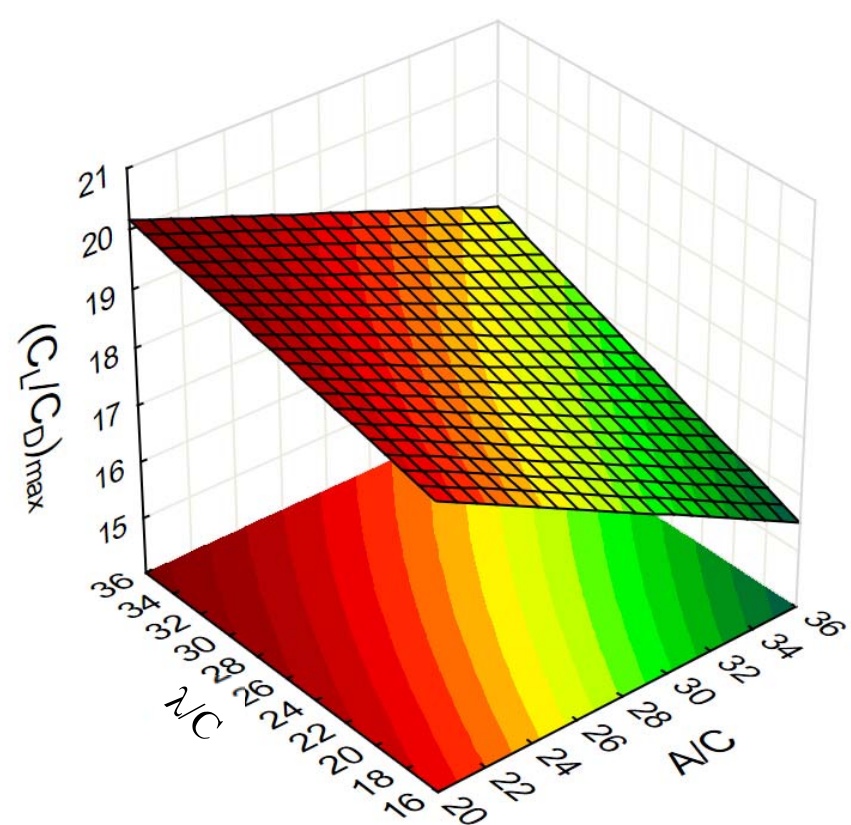

Fig.10, Effect of serration amplitude and wavelength on lift-to-drag-ratio $\left(C_{L} / C_{D}\right)_{M a x}$. Linear model is based on factorial core as indicated in Table 2.

Recent literature regularly states LE serration to be beneficial in achieving high maximum post-stall lift $25 ; 7 ; 10$. This could be partly confirmed to be of significant dimension in the conducted experimental investigation (Table 2) for the A12 226 serration. The obtained lift, however, for all the other serrations did not exceed the baseline lift (at constant representative surface area), but show a more even transition towards the post-stall region. Moreover, a delay

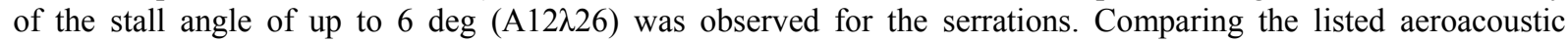

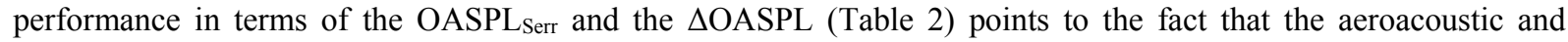
aerodynamic optimum compete with each other.

American Institute of Aeronautics and Astronautics 
Table 2, Experimental aeroacoustic and aerodynamic results at $\operatorname{Re}=250,000, T u=2.1 \%$ and $\mathrm{z} / \mathrm{H}=0.128$.

\begin{tabular}{|c|c|c|c|c|c|c|c|c|}
\hline & Serr & OASPLSerr & $\triangle \mathrm{OASPL}$ & $C_{L}$ Max & $\left(\mathrm{C}_{\mathrm{L}} / \mathrm{C}_{\mathrm{D}}\right)_{\text {Max }}$ & AoAzero CL & CL Zero AoA $_{\text {L }}$ & AoACrit \\
\hline & -- & $d B$ & $d B$ & -- & -- & $\operatorname{deg}$ & -- & deg \\
\hline \multirow{4}{*}{ 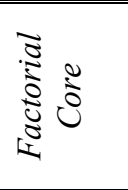 } & $A 22 \lambda 18$ & 58.00 & 3.80 & 1.11 & 18.76 & -7.0 & 0.54 & 11 \\
\hline & $A 35 \lambda 18$ & 55.68 & 5.89 & 1.08 & 15.91 & -8.2 & 0.57 & 11 \\
\hline & $A 22 \lambda 34$ & 58.98 & 2.81 & 1.16 & 19.80 & -6.2 & 0.52 & 14 \\
\hline & $A 35 \lambda 34$ & 56.54 & 4.99 & 1.14 & 17.64 & -7.7 & 0.56 & 11 \\
\hline Central & $A 29 \lambda 26$ & 57.22 & 4.47 & 1.08 & 17.39 & -7.6 & 0.55 & 12 \\
\hline \multirow{4}{*}{ 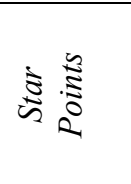 } & $A 12 \lambda 26$ & 60.15 & 1.90 & 1.25 & 19.86 & -5.8 & 0.54 & 14 \\
\hline & $A 29 \lambda 7.5$ & 56.49 & 5.09 & 0.91 & 14.59 & -7.7 & 0.48 & 10 \\
\hline & $A 45 \lambda 26$ & 54.49 & 6.98 & 1.01 & 16.42 & -7.6 & 0.50 & 10 \\
\hline & $A 29 \lambda 45$ & 58.69 & 2.84 & 1.15 & 19.93 & -7.3 & 0.59 & 11 \\
\hline Baseline & $B S L N$ & 61.64 & -- & 1.24 & 22.51 & -5.5 & 0.64 & 8 \\
\hline
\end{tabular}

\section{B. Pressure Distribution}

The pressure run along the aerofoil chord was extracted at spanwise locations of the serration peak, midpeak and trough. Generally, the serration parameters mainly influence the pressure run along the aerofoil suction side where no significant deviations to the baseline case were found for the pressure side. This is comprehensible as the serrations have a semi-cyclic shape and mainly affect the three-dimensional geometry on the suction side. Although the serrations geometrically alter the shape of the aerofoil leading edge to a chordwise maximum of up to $\mathrm{x} / \mathrm{C}=0.3$, they show a significant effect on the pressure distribution to distances of $\mathrm{x} / \mathrm{C} \leq 0.45$ for the pressure side and $\mathrm{x} / \mathrm{C} \leq 0.6$ for the suction side (Fig. 11). The maximum pressure on the aerofoil suction side rises steadily in the spanwise direction from peak to trough of the serration. This spanwise pressure gradient is supposed to be an indicator for a spanwise secondary flow as the flow is deflected towards the serration trough. Moreover, the increased pressure coefficients towards the trough indicate increased local lift forces (Eq. 8, Table 3).

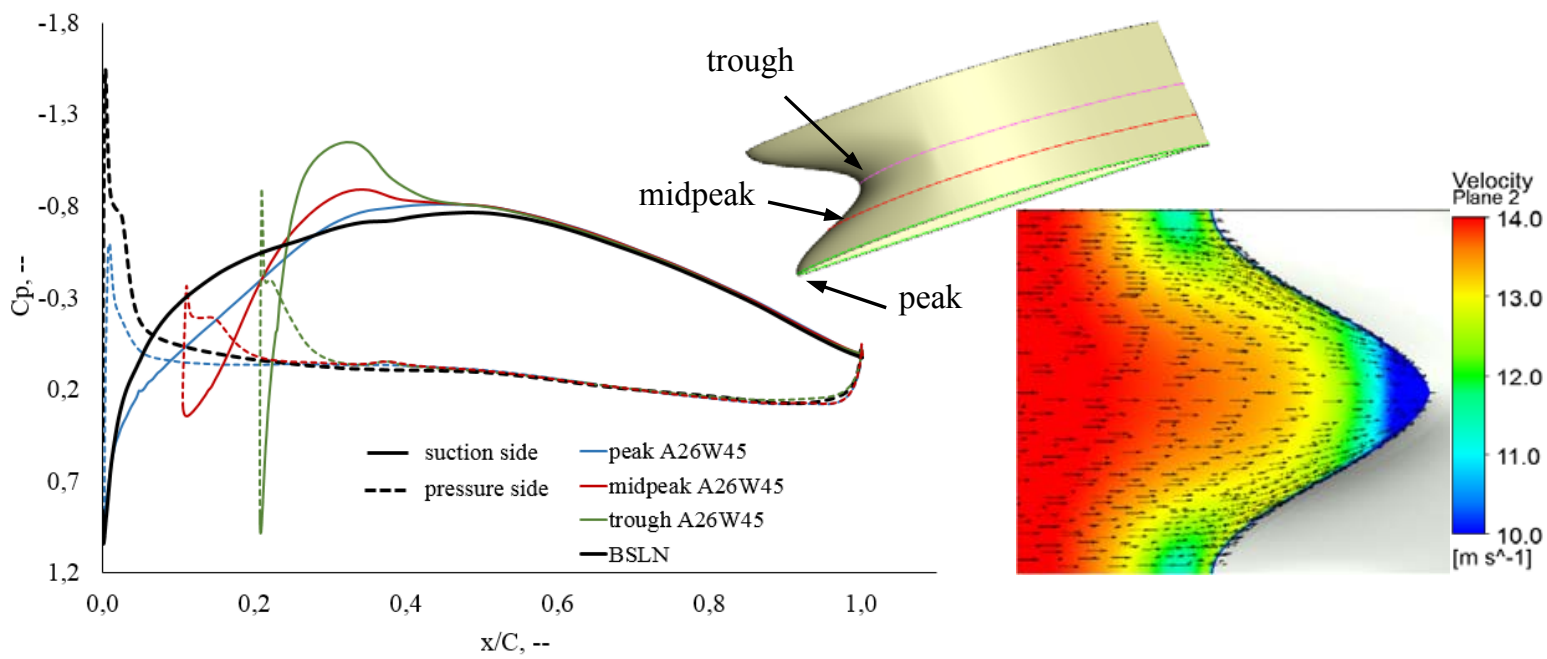

Fig.11, Pressure distribution of A26 $\lambda 45 \mathrm{LE}$ at distinct spanwise locations. Additional plot of baseline case, $\mathrm{z} / \mathrm{H}=\mathbf{0}, \operatorname{Re}=\mathbf{1 5 0 , 0 0 0}, \mathrm{Tu}=\mathbf{5 \%}$.

The numerically obtained findings can be compared to experimental PIV-results, conducted at Brunel University London $^{13}$, where the distribution of the vertical velocity components $\left(\mathrm{u}_{\mathrm{w}}\right)$ was captured at six distinct streamwise locations for a serrated aerofoil of A45 26 . Starting upstream the aerofoils leading edge (POS $-5 \mathrm{~mm}$ and POS $-1 \mathrm{~mm}$ ) a delay in the flow velocity for the region close to the leading edge becomes visible due to the close proximity to the stagnation point. After first entering the serration interstices (POS $+2 \mathrm{~mm}$ ), the main peak of the velocity is well beneath the LE tip, indicated by the dashed lines in Fig. 12. Increasing the streamwise position within the serration shows a shift of the main peak upwards towards the suction side.

American Institute of Aeronautics and Astronautics 
The closer the plane is to the serration root, the higher the influence of the serration on the fluid above the aerofoil. The results show that the region of high velocity (i.e. secondary flow) tends to expand outwards. The velocity plots also indicate that the absolute magnitude increases with the streamwise distance. This is probably due to the tendency of flow being accelerated either upward or downward away from the serration, thus avoiding large-scale impingement to the serration root, what matches the numerically obtained pressure run along the aerofoil chord (Fig. 11).

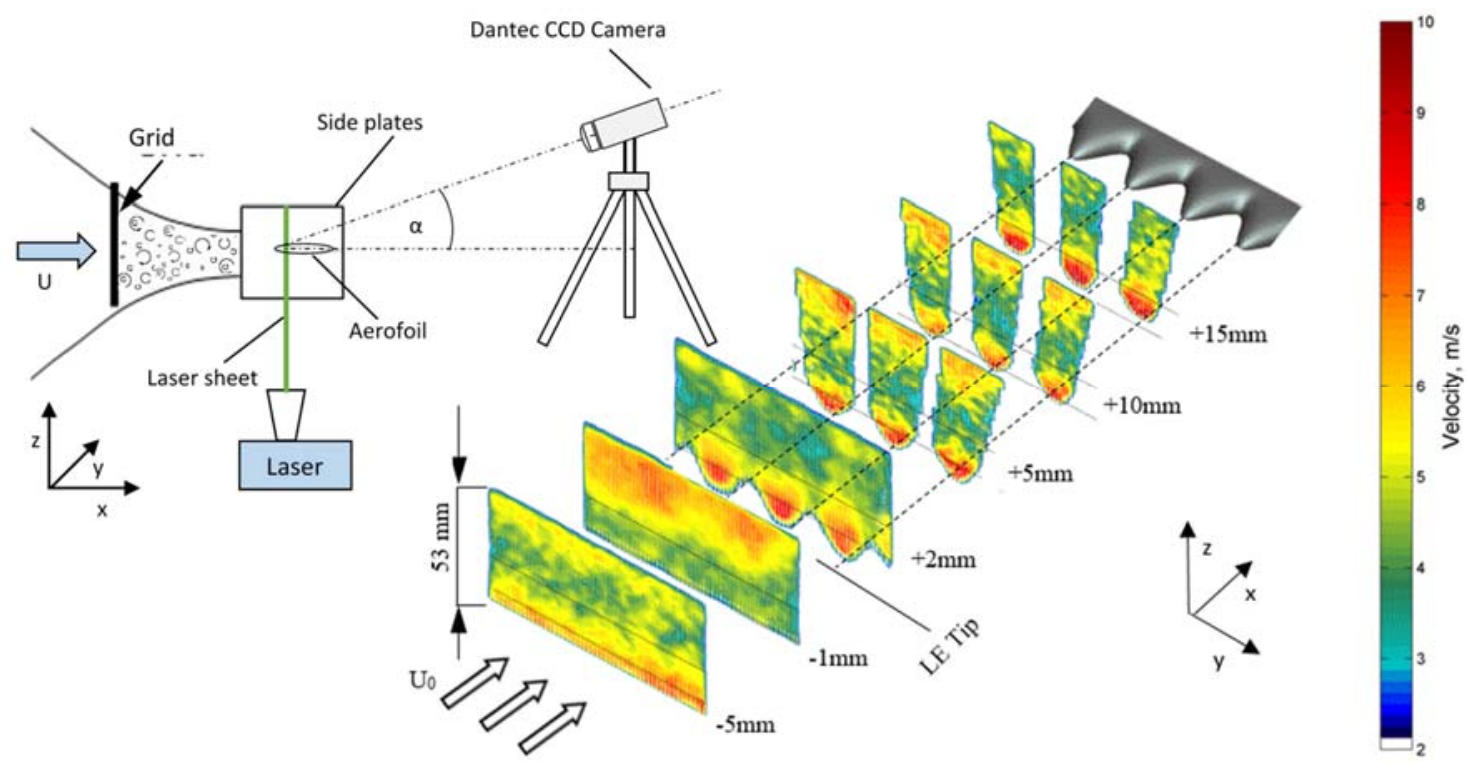

Fig.12, Trend of vertical velocity distribution $u_{w}$ along different streamwise locations by use of an $\mathbf{A} / \mathbf{C}=0.3$, $\lambda / \mathrm{C}=0.175(\mathrm{~A} 45 \lambda 26)$ leading edge. $\mathrm{Re}=\mathbf{2 0 0 , 0 0 0}, \mathrm{Tu}=5.5 \%, \mathrm{z} / \mathrm{H}=0$. Experimentally obtained flow patterns by use of the PIV technique.

Figure 13 shows a more detailed analysis of the pressure distribution at spanwise locations of the serration peak and trough for different angles of attack. It can be seen, that the serration amplitude influences the pressure distribution in the region of the leading edge up to $\mathrm{x} / \mathrm{C} \approx 0.6$, where minimum amplitudes were found to influence the pressure distribution only until $\mathrm{x} / \mathrm{C}=0.4$. This observation can mainly be linked to the larger chordwise area, which is cropped out of the aerofoil at high amplitudes. The serration wavelength, on the contrary, does not influence the $\mathrm{x} / \mathrm{C}$ pressure distribution, while a maximum wavelength leads to maximum amplitudes of the pressure coefficients. At zero angle of attack no distinct influence of altering amplitude or wavelength on the pressure run was observed for the peak location, whereas a deviant behaviour was observed for the trough location where maximum amplitudes and wavelengths lead to an increase of lift or the negative pressure coefficients, respectively. The influence of serration amplitude and wavelength becomes more prominent towards higher angles of attack. At minimum wavelengths and maximum amplitudes, the inclination angle of the serration is at its maximum and the fluid is deflected towards the serration trough with high impact (max. gradient dy/dx) what leads to strong three-dimensional flow effects and thus reduced pressure coefficients for the peak region but high values of lift for the trough region. This pattern can also be confirmed qualitatively by the performed PIV experiments ${ }^{13}$, where maximum wavelengths showed to lead to a high acceleration of the fluid within the serration interstices. Albeit a maximum amplitude and small wavelengths are identified to be beneficial for high negative pressure coefficients and thus lift, the loss in effective surface area compared to the baseline case cannot be compensated, leading to a drop in the overall lift. 

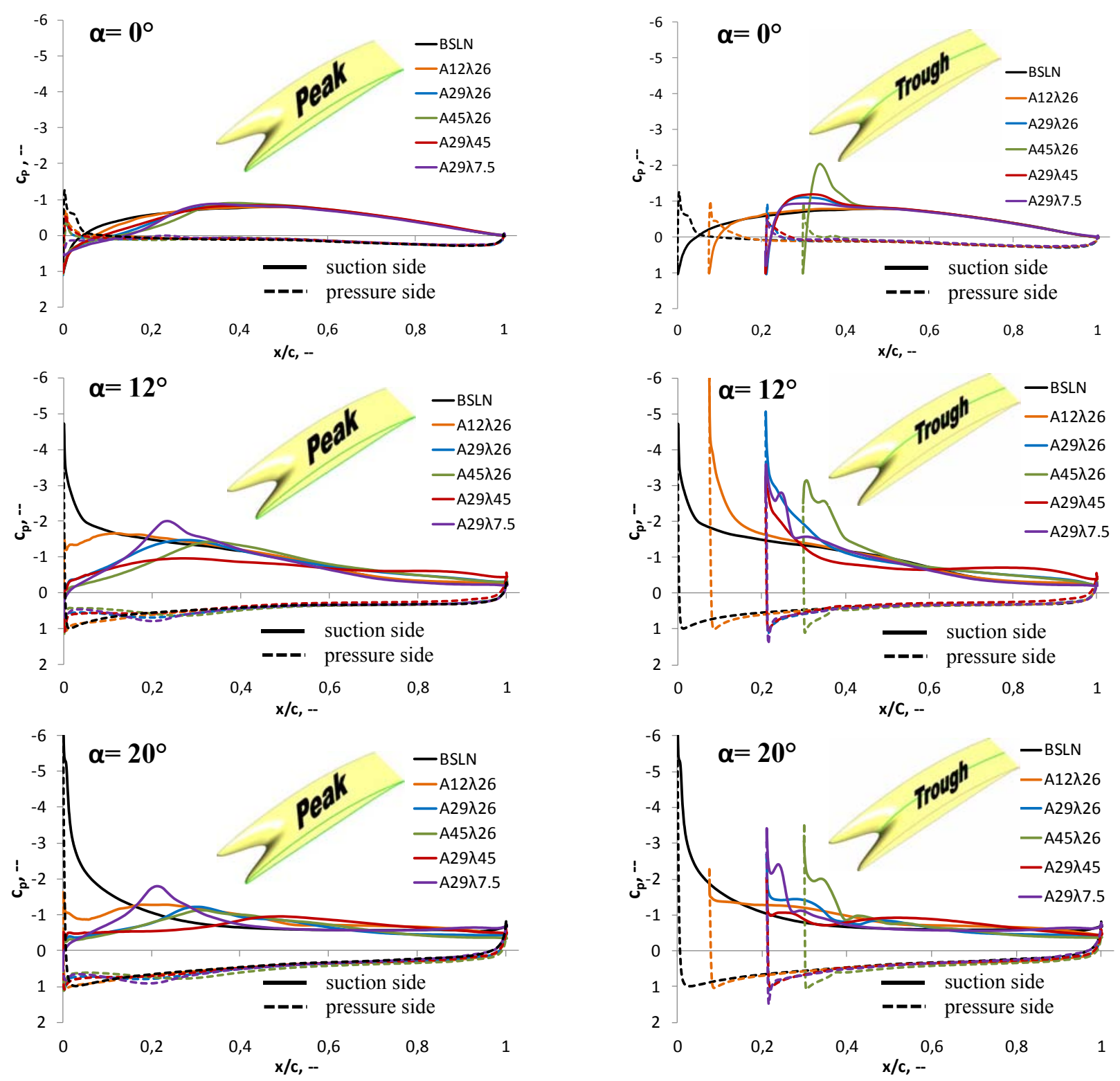

Fig.13, Numerically extracted pressure distribution along non-dimensional aerofoil chord at different spanwise locations (peak and trough) as well as different angles of attack (0, 12, $20 \mathrm{deg})$. Comparison of baseline and serrations at $\operatorname{Re}=150,000$.

\section{Separation Process via Skin Friction Coefficients}

At post-stall both, numerical and experimental results show high coefficients of lift for the serrations where the lift drops significantly for the baseline case. This performance might be attributed to a different separation process with leading edge serrations. In the current study, the separation is detected by the skin friction coefficient as per Eq. 7 , where values of zero indicate a separated flow. The trend of separation for different serrations as well as the baseline is shown in Fig. 14.

$$
c_{F}=\frac{\tau_{w}}{1 / 2 \cdot \rho \cdot U_{0}^{2}}
$$


For the baseline case, an increasing angle of attack results in a continuous shift of the separation point towards the aerofoil leading edge. Consequently, the lift coefficient drops as the boundary layer is no longer attached to the aerofoils surface. Moving the focus towards serrated leading edges, the process of separation shows a more threedimensional pattern.
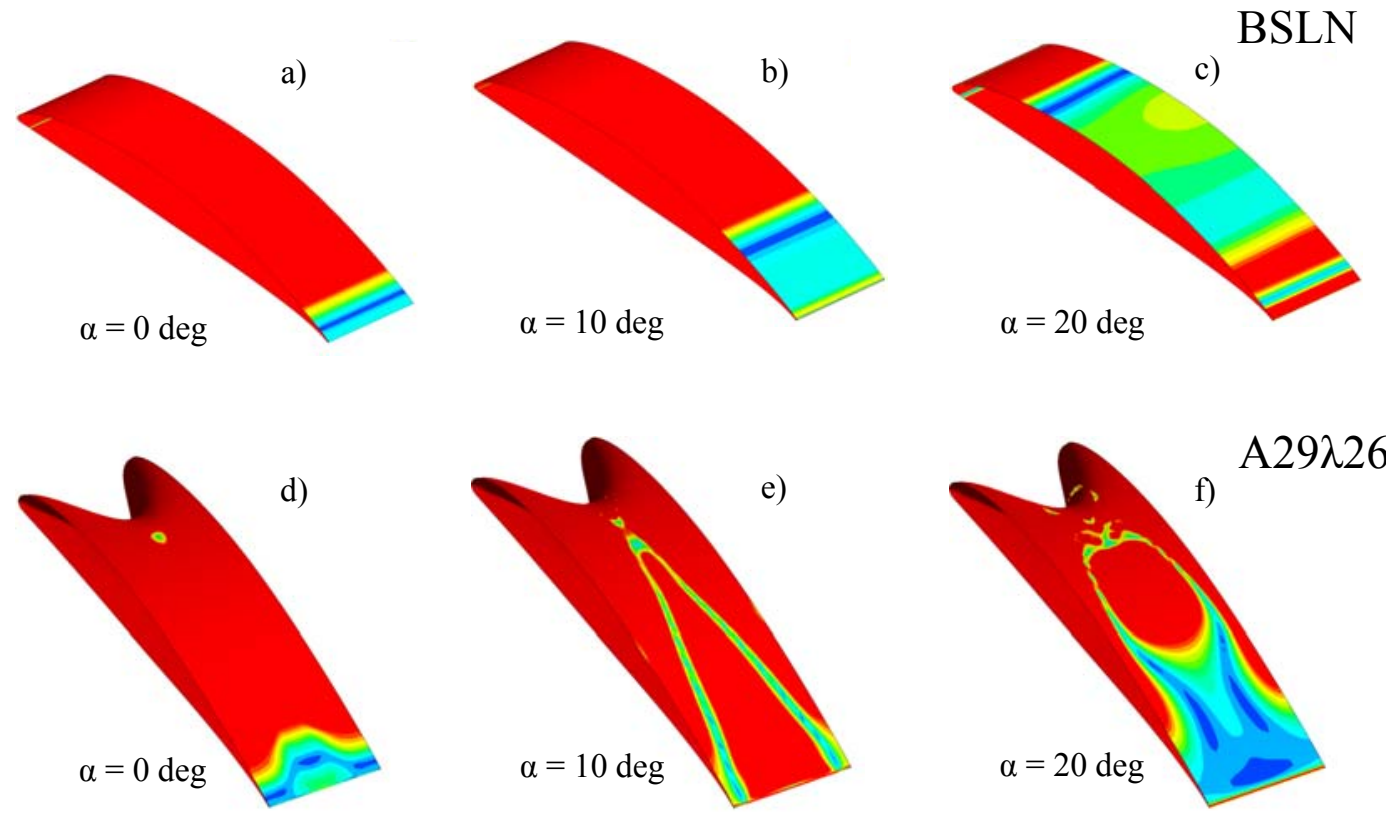

Skin Friction $\mathrm{C}_{\mathrm{L}}$
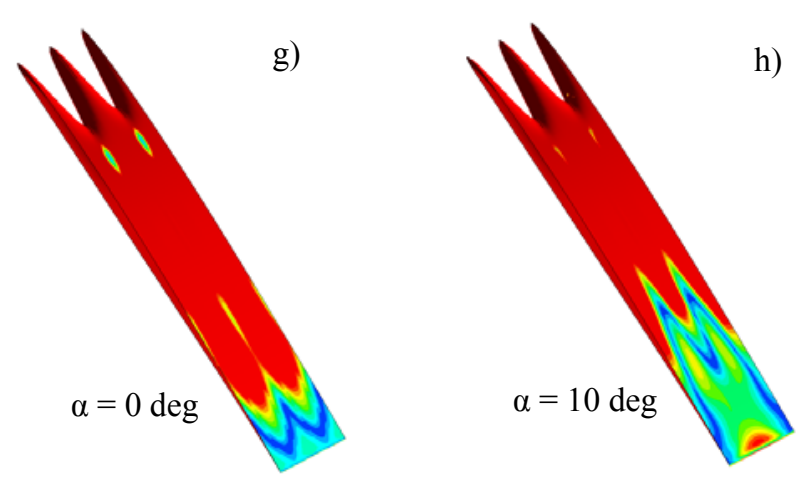

A29ג7.5
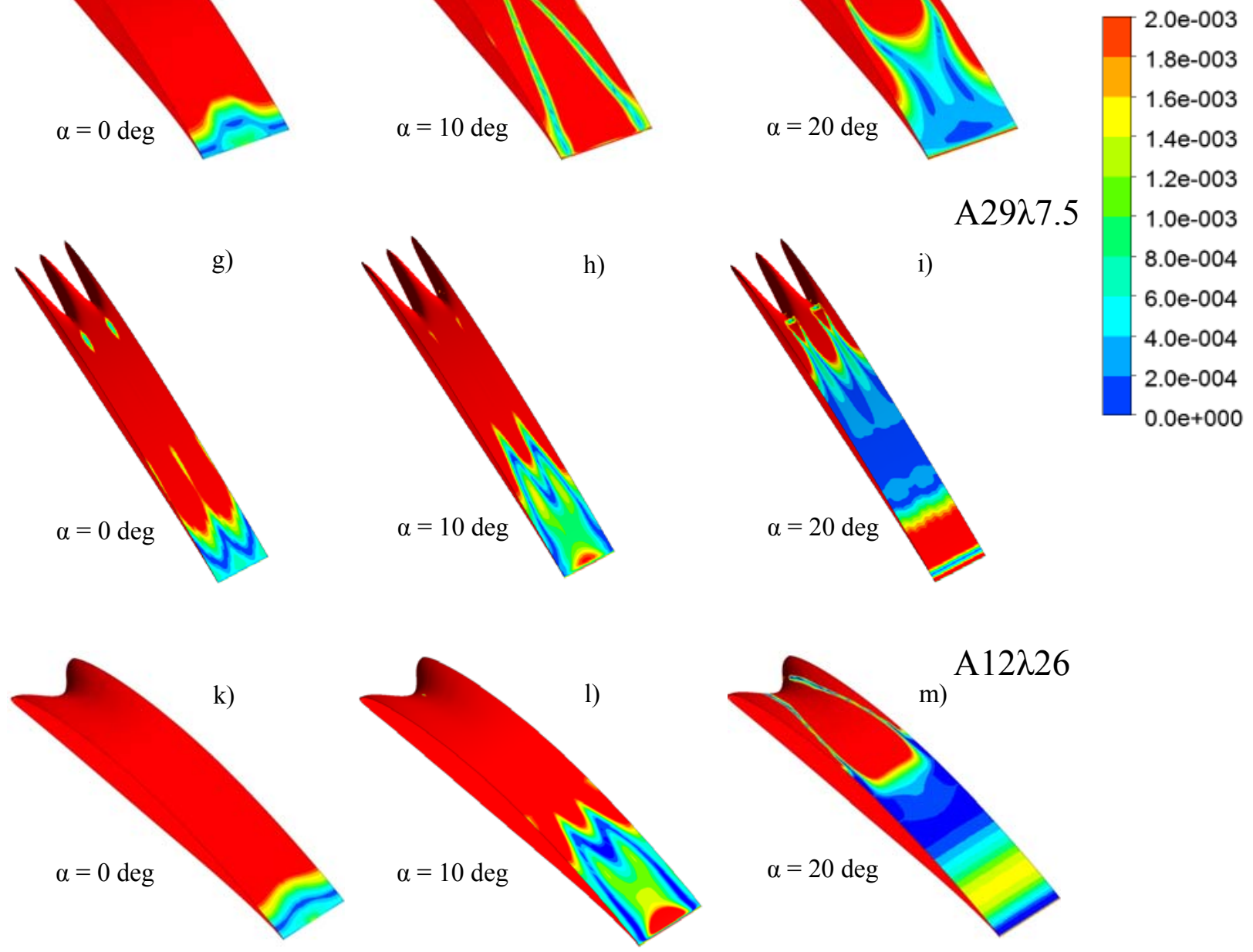

Fig 14, Skin friction coefficients at different angles of attack. Comparison of baseline leading edge (a - c) and

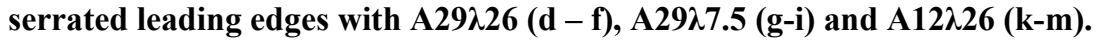

American Institute of Aeronautics and Astronautics 
At spanwise positions close to the serration root, the trend of separation is similar to that of the baseline case. However, at spanwise positions closer to the serration peak, the point of separation remains at positions close to the aerofoil trailing edge, leading only to a partial separation of the flow for serrated leading edges at high AoA. This pattern is suspected to be the cause for the much more stable lift coefficients at post-stall. The observed local separation for serrated aerofoils shows to be highly sensitive to the serration parameters amplitude and wavelength. Small amplitudes reduce the three-dimensional separation process towards a baseline-like performance, where, in particular at very high angles of attack, the point of separation migrates over the whole aerofoil chord towards the aerofoil leading edge as it is also the case for small serration wavelengths. The numerically determined lift coefficients for different AoA as

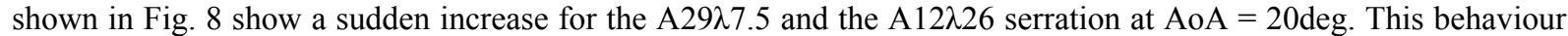
can be explained by evaluating the skin friction coefficients (Fig. 14), where it can be seen that the flow starts to reattach at the analysed maximum angle of attack, leading to an increase of the lift forces, albeit this effect could not be confirmed experimentally.

The influence of the separation on the lift coefficients becomes even more distinct when analysing the local lift coefficients (Eq. 8), based on the local pressure distribution along the aerofoil chord at spanwise peak, midpeak and trough locations (Fig. 11). As it is indicated by Table 3, the local lift remains almost constant along the span for the

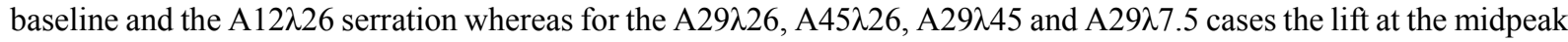
position shows significant higher values compared to the trough and peak positions.

$$
C_{L}=-\int_{X / C=0}^{X / C=1}\left(c p_{\text {suction }}-c p_{\text {pressure }}\right) d\left(\frac{X}{C}\right)
$$

The A29 445 and A29 $\lambda 7.5$ show the smallest loss in lift performance when altering the angle of attack from $12 \mathrm{deg}$ to $20 \mathrm{deg}$, indicating that the serration wavelength does not play a prominent role in terms of sensitivity to the AoA. When analysing the trend of the local lift over the aerofoil span, however, high amplitudes effectuate maximum lift coefficients. Particularly interesting is the occurrence of high lift coefficients at the locations of the midpeak. This leads to the conclusion that at the midpeak an optimum of lift and chord length is reached, resulting in maximum lift coefficients as defined by Eq. 8, albeit the local pressure coefficients are lower than at the serration trough.

Table 3, Local lift coefficients, based on the local aerofoil chord length by use of numerically obtained data

\begin{tabular}{|c|c|c|c|c|}
\hline & AoA & $\mathrm{C}_{\text {L,PEAK }}$ & C $_{L, M I D P E A K}$ & C $_{\text {L,Trough }}$ \\
\hline & $\circ$ & -- & -- & -- \\
\hline \multirow{3}{*}{$B S L N$} & 12 & 1,44 & 1,44 & 1,44 \\
\hline & 20 & 1,36 & 1,36 & 1,36 \\
\hline & $\Delta C_{L}$ & 0,08 & 0,08 & 0,08 \\
\hline \multirow{3}{*}{$A 12 \lambda 26$} & 12 & 1,41 & 1,46 & 1,42 \\
\hline & 20 & 1,33 & 1,37 & 1,32 \\
\hline & $\Delta C_{L}$ & 0,08 & 0,10 & 0,11 \\
\hline \multirow{3}{*}{$A 29 \lambda 26$} & 12 & 1,26 & 1,41 & 1,33 \\
\hline & 20 & 1,14 & 1,23 & 1,10 \\
\hline & $\Delta C_{L}$ & 0,12 & 0,19 & 0,22 \\
\hline \multirow{3}{*}{$A 45 \lambda 26$} & 12 & 1,18 & 1,47 & 1,31 \\
\hline & 20 & 1,16 & 1,40 & 1,17 \\
\hline & $\Delta C_{L}$ & 0,02 & 0,08 & 0,14 \\
\hline \multirow{3}{*}{$A 29 \lambda 45$} & 12 & 1,14 & 1,27 & 1,20 \\
\hline & 20 & 1,13 & 1,23 & 1,10 \\
\hline & $\Delta C_{L}$ & 0,01 & 0,05 & 0,10 \\
\hline \multirow{3}{*}{ A29ג7.5 } & 12 & 1,20 & 1,33 & 1,24 \\
\hline & 20 & 1,22 & 1,27 & 1,13 \\
\hline & $\Delta C_{L}$ & $-0,02$ & 0,06 & 0,11 \\
\hline
\end{tabular}




\section{Numerical Aeroacoustics}

As a first attempt towards numerical aeroacoustics, transient scale adaptive simulations (SAS) were performed where the region in close proximity to the aerofoil leading edge and thus to the serrations was resolved via zonal large eddy simulations (Z-LES). The high inlet turbulence was generated synthetically (via a harmonic flow generator HFG) where the Spectrum by von Kármán was used for mode amplitudes $\hat{u}_{n}$ as stated in Eq. 9, where $\kappa$ is the angular wavenumber and EK the corresponding turbulent energy ${ }^{26 ; 27}$. The statistical properties of the synthetic velocity fluctuations (length and time-scales) correspond to the RANS solution upstream the zonal LES. This approach is expected to provide a deepened insight into the noise generating and reduction mechanisms close to the tip and the root of the serrations. Preliminary analysis of the generated turbulence field as a function of the mesh dimensions and the temporal resolution show a good match with both, the von Kármán and the Liepmann turbulence spectrum in the relevant frequency range as it is shown in Fig. 15.

$$
\hat{u}_{n}=2 \cdot \sqrt{E\left(\kappa_{n}\right) \Delta \kappa}
$$

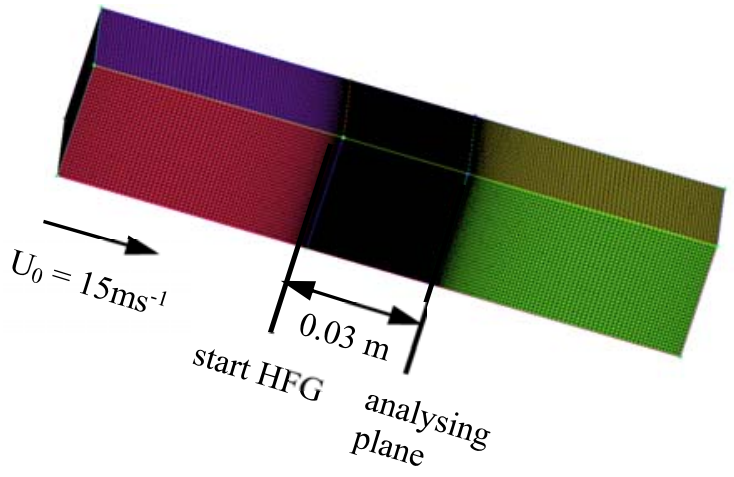

a)

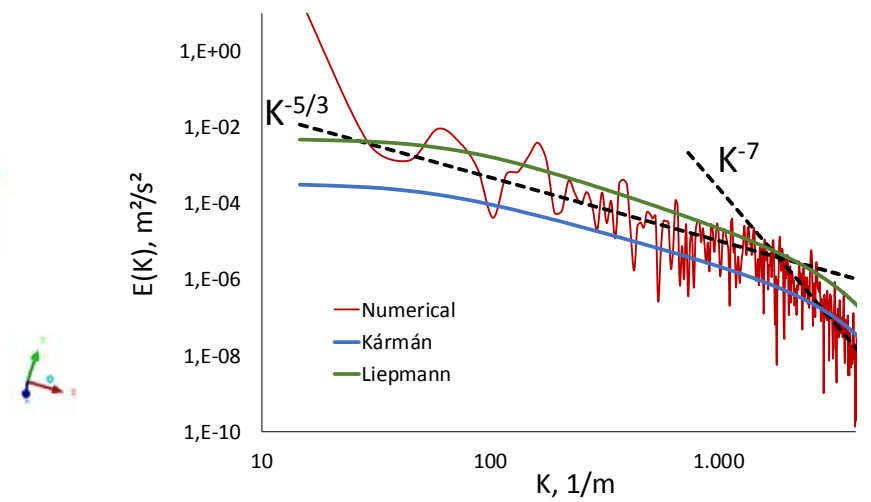

b)

Fig.15, a) Test domain with synthetically generated turbulence field (via a harmonic flow generator) by use of the compressible SAS-SST approach. b) Resulting turbulence energy spectrum and comparison to the theoretical approach by Von Kármán and Liepmann.

For the simulation of the interaction of incoming turbulence with the serrated leading edge, synthetic turbulence was introduced $100 \mathrm{~mm}$ upstream the aerofoil leading edge tip. Figure 16 shows the incoming turbulent structures for three different time steps by means of the Q-Criterion, coloured by the free stream velocity. For the purpose of analysis, a number of 187 monitor points was implemented in the region of the serrated leading edge in order to monitor the pressure and velocity fluctuations at a transient stepsize of $\Delta \mathrm{t}=2 \cdot 10^{-5} \mathrm{~S}$. 

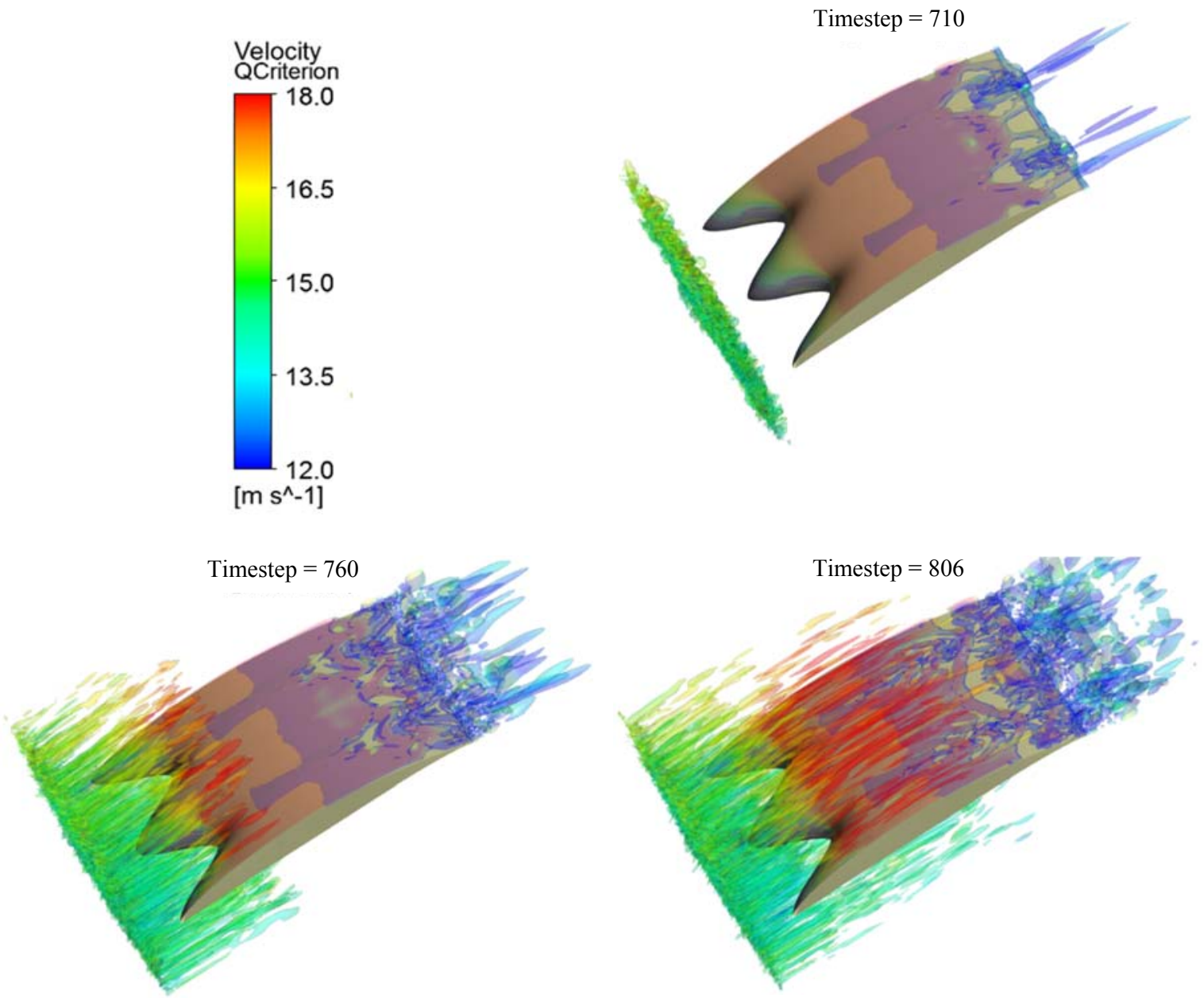

Fig.16, Transient numerical results by use of the SAS-SST approach, including the generation of synthetic turbulence in accordance to the isotropic von Kármán turbulence spectrum. Displayed Q-Criterion at $Q=$ $1 \cdot 10^{5} \mathrm{~s}^{-2}$ coloured by the mean flow velocity $U_{0}$.

Due to the high computational cost and the high amount of generated data only exemplary results at a frequency resolution of $\Delta \mathrm{f}=32 \mathrm{~Hz}$ can be presented at the moment. Figure 17 shows the power spectral density of the flow velocity for different positions along the aerofoil span where the $x$-wise position is set fixed at $5 \mathrm{~mm}$ in front of the leading edge tip (Fig. 17a) and flushed to the leading edge tip (Fig. 17b). Positions of $z=0$ and $z=45 \mathrm{~mm}$ indicate the peak of the serration, whereas $\mathrm{z}=22.5 \mathrm{~mm}$ represents the root of the serration. From the current status of the postprocessing it can be said, that the velocity fluctuations of high energy focus on the low frequency region $\mathrm{f} \leq 1000 \mathrm{~Hz}$, where a transition towards low energy levels occurs at $1 \mathrm{kHz} \leq \mathrm{f} \leq 4 \mathrm{kHz}$. The slope of the decreasing energy level seems to be affected by the spanwise location, where the maximum transition area occurs close to the serration peak. Comparing two different streamwise locations, namely $5 \mathrm{~mm}$ in front of the leading edge tip (Fig. 17a) and flushed to the leading edge (Fig. 17b) exhibits clear differences in the spectra. In direct proximity to the leading edge tip at the spanwise location of the serration peak a distinct peak appears at $\mathrm{f} \approx 6.5 \mathrm{kHz}$, indicating velocity fluctuations of small temporal span but of high energy. This specific pattern can be assigned to the forced deflection of the flow towards the serration root. Apart from the location of the serration amplitude, moving along the span shows only minor differences in the velocity spectra. 


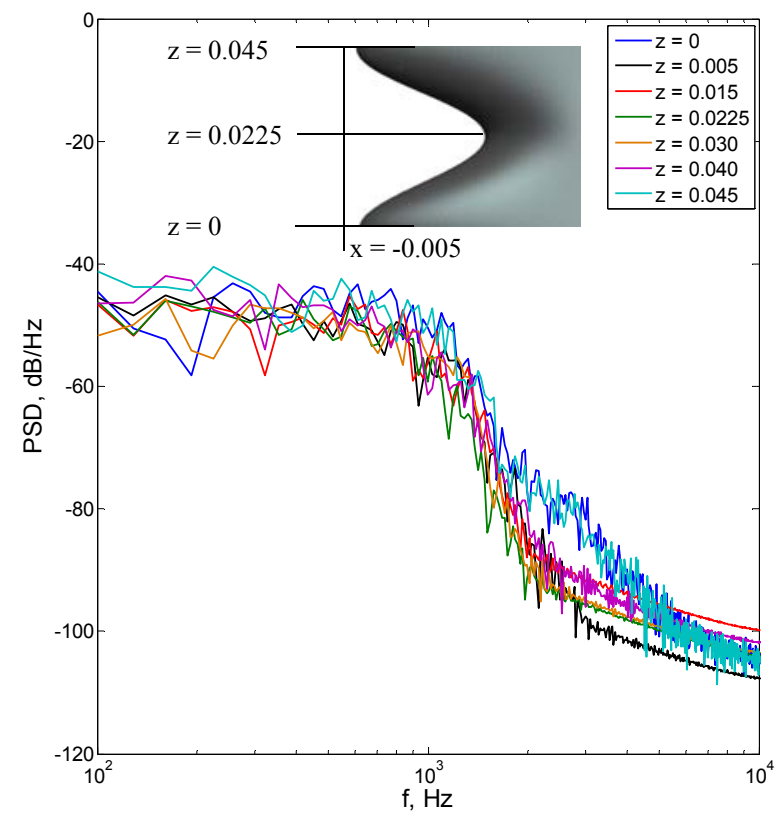

a)

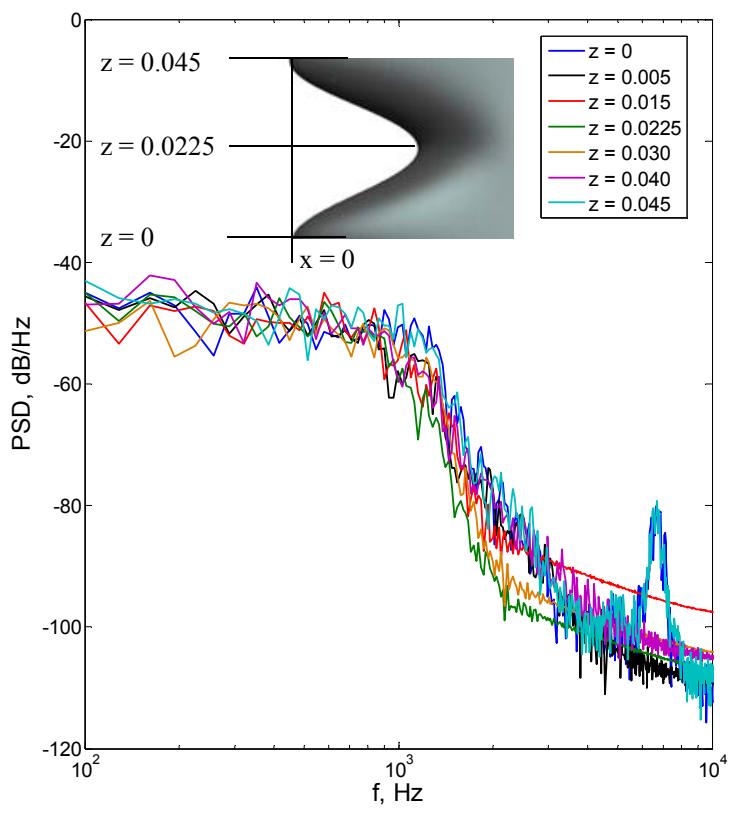

b)

Fig.17, Power spectral density of the velocity along the aerofoil span of an A29 $\lambda 45$ serration at streamwise location of a) $5 \mathrm{~mm}$ and b) $0 \mathrm{~mm}$ upstream the aerofoils leading edge tip.

\section{Polyoptimising Aeroacoustics and Aerodynamics}

In the aeroacoustic study, characteristic flow parameters such as Re number and turbulence intensity as well as geometrical parameters in form of serration amplitude, serration wavelength and the angle of attack were analysed as an interrelated system. In terms of aerodynamic performance, preliminary numerical studies identified the Tu not to be of major importance to the lift and drag coefficients. Furthermore, the angle of attack showed to be no main parameter in terms of noise radiation and noise reduction although a zero angle of attack yields an insignificantly improved noise reduction capability. Therefore, a higher degree of freedom is achieved by freely choosing the Tu according to aeroacoustics and the AoA according to optimum aerodynamic features. Due to the limited number of analysed Reynolds numbers, an optimisation of aeroacoustic and aerodynamic performance was defined based on the serration design parameters wavelength and amplitude.

The factorial core of the aeroacoustically analysed experimental space was extracted and fed with experimentally obtained aerodynamic data (Table 2). Figure 18 shows the polyoptimum of the analysed parameters. While a maximum amplitude yields the maximum noise reduction, a minimum lift-to-drag ratio $\left(\mathrm{C}_{\mathrm{L}} / \mathrm{C}_{\mathrm{D}}\right)_{\mathrm{Max}}$, minimum lift coefficients $\mathrm{C}_{\mathrm{L}, \operatorname{Max}}$ and a decrease of the maximum pre-stall angle are unwanted attending ills. Equal trends arise for the aeroacoustically desirable small serration wavelengths, although the aeroacoustic effect of the wavelength is smaller compared to the amplitude. Weighting the response variables of OASPLSerr, $\triangle \mathrm{OASPL},\left(\mathrm{C}_{\mathrm{L}} / \mathrm{C}_{\mathrm{D}}\right)_{\mathrm{Max}}, \mathrm{AoA}_{\mathrm{Crit}}$ and $\mathrm{C}_{\mathrm{L} \text {,Max }}$ equally and maximising the resulting linear system of equations yields an optimum serration amplitude of intermediate size $(\mathrm{A} / \mathrm{C}=0.19)$ while the serration wavelength should be either of a high value $\lambda / \mathrm{C}=0.23$ (best aerodynamics $)$ or of intermediate size $(\lambda / \mathrm{C}=0.175$; high noise reduction while maintaining good aerodynamic features). 

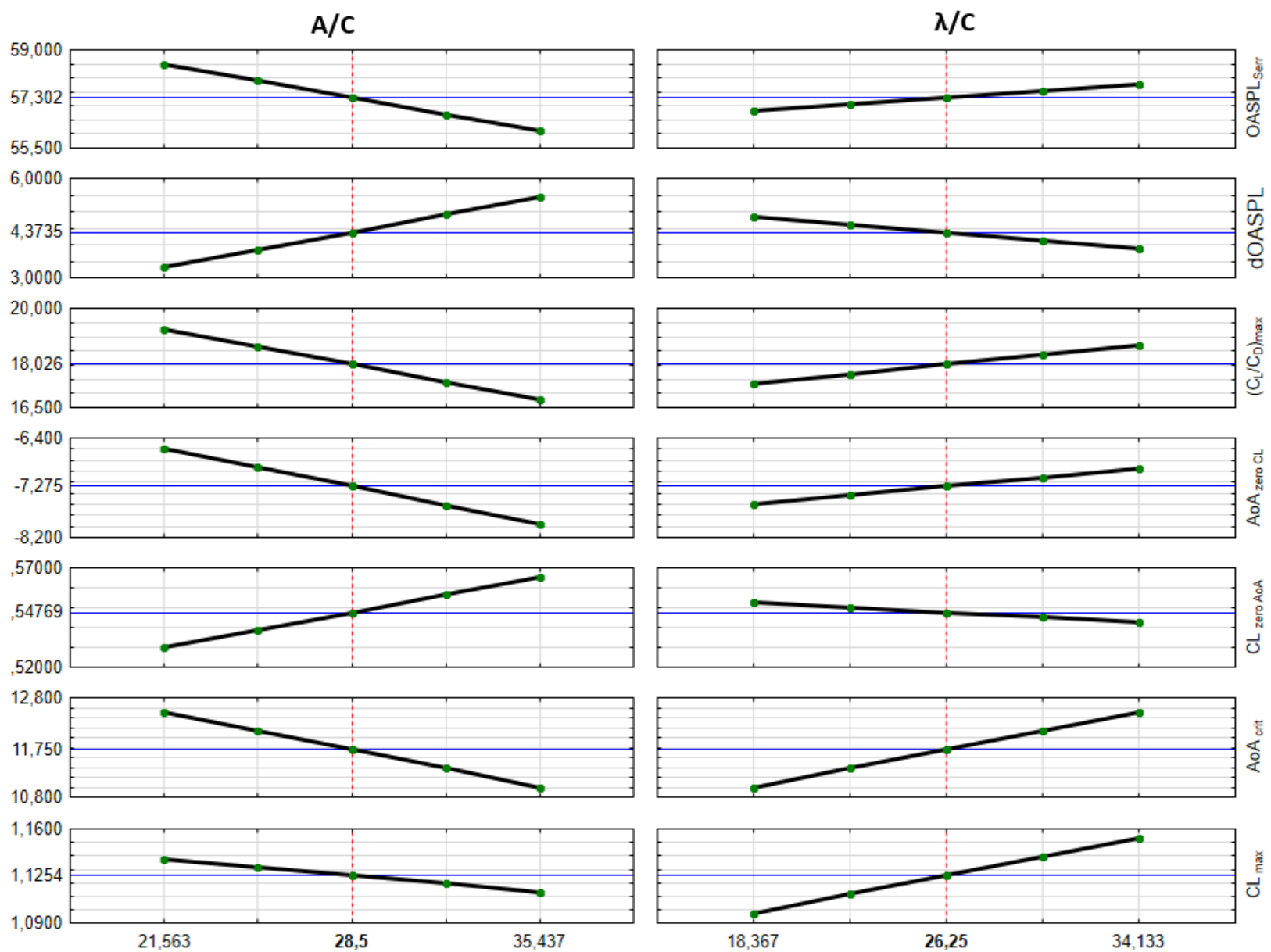

Fig.18, Polyoptimum of aeroacoustic and aerodynamic performance at $\operatorname{Re}=2.5 \cdot 10^{5}, \mathrm{Tu}=2.1 \%$ and $\mathrm{z} / \mathrm{H}=$ 0,128 as a function of serration amplitude $(\mathrm{A} / \mathrm{C})$ and serration wavelength $(\lambda / \mathrm{C})$. Optimised algorithm is based on aerodynamic results, extracted of the factorial core (Table 2). 


\section{Conclusion}

An existing aeroacoustic study was expanded towards an optimum of low-noise LE serrations and a maximum noise reduction capability of serrated LE. Additionally, a numerical and experimental study by use of serrated LE configurations was performed in order to gather information on the aerodynamic performance in terms of lift, drag and critical AoA. After validating both studies by comparison, the aeroacoustic and the aerodynamic results were combined in order to define a multi-objective problem through efficient noise reduction and reasonable aerodynamic performance. Finally, a detailed analysis of the separation process as well as of the local pressure distribution was carried out, including a first attempt towards numerical aeroacoustics. The results achieved allow the current paper to reach the following conclusions:

- An optimum of noise radiation and noise reduction is achieved by keeping the Re number and the Tu on low levels and by choosing a serration design of maximum amplitude and minimum / intermediate wavelength. Main factors are $\mathrm{Re}$ and $\mathrm{A} / \mathrm{C}$, followed by $\mathrm{Tu}, \lambda / \mathrm{C}$ and $\mathrm{z} / \mathrm{H}$.

- The angle of attack represents a mainly aerodynamic design parameter; the aeroacoustic performance is only affected to low degrees.

- The numerically obtained pressure distribution along the aerofoil span shows a high dependency on the serration design where, in general, the maximum pressure on the aerofoil suction side rises steadily in the spanwise direction from peak to trough of the serration and is supposed to be an indicator for a spanwise secondary flow. Moreover, the extracted pressure enables a determination of local lift coefficients for the serrations and thus facilitates an effective local optimisation of the serration shape.

- The serration wavelength shows no high effect on lift and drag coefficients.

- Delayed maximum stall angles were observed by comparing serrated LE with the baseline case. The maximum stall angle was achieved at large serration wavelengths and small serration amplitudes.

- In contrast to the baseline case, the smooth transition of the lift coefficients towards the post-stall region of the serrations could be identified to be due to a complex separation process, visualised by the skin friction coefficients.

- The defined polyoptimum of aeroacoustic and aerodynamic performance as a function of amplitude and wavelength yields intermediate amplitudes and high to intermediate wavelengths to be beneficial for reaching high noise reduction while maintaining a good aerodynamic performance.

- The early state transient simulations provide first insights into the relationship between serration design and the spectral shape of the velocity fluctuations. 


\section{References}

${ }^{1}$ Chong, T. P., Vathylakis, A., McEwen, A., Kemsley, F., Muhammad, C., et al., “Aeroacoustic and Aerodynamic Performances of an Aerofoil Subjected to Sinusoidal Leading Edges," 2015.

${ }^{2}$ Hersh, A. S., Sodermant, P. T., and Hayden, R. E., "Investigation of Acoustic Effects of Leading-Edge Serrations on Airfoils," Journal of Aircraft, Vol. 11, No. 4, 1974, pp. 197-202.

${ }^{3}$ Kim, M. J., Yoon, H. S., Jung, J. H., Chun, H. H., and Park, D. W., "Hydrodynamic characteristics for flow around wavy wings with different wave lengths," International Journal of Naval Architecture and Ocean Engineering, Vol. 4, No. 4, 2012.

${ }^{4}$ Lau, A. S., Haeri, S., and Kim, J. W., "The effect of wavy leading edges on aerofoil-gust interaction noise," Journal of

Sound and Vibration, Vol. 332, No. 24, 2013, pp. 6234-6253.

${ }^{5}$ Narayanan, S., Chaitanya, P., Haeri, S., Joseph, P., Kim, J. W., et al., "Airfoil noise reductions through leading edge serrations," Physics of Fluids, Vol. 27, No. 2, 2015, p. 25109.

${ }^{6}$ Narayanan, S., Joseph, P., Haeri, S., and Kim, J. W., "Noise Reduction Studies from the Leading Edge of Serrated Flat Plates," 20th AIAA/CEAS Aeroacoustics Conference, 2014.

${ }^{7}$ Pedro, H. T., and Kobayashi, M. H., "Numerical Study of stall delay on humpback whale flippers," 46th AIAA Aerospace Sciences Meeting and Exhibit, 2008.

${ }^{8}$ Polacsek, C., Reboul, G., Clair, V., Le Garrec, T., and Deniau, H., "Turbulence-airfoil interaction noise reduction using wavy leading edge: An experimental and numerical study," Inter Noise 2011, 2011.

${ }^{9}$ Roger, M., Schram, C., and Santana, L. de, "Reduction of Airfoil Turbulence-Impingement Noise by Means of LeadingEdge Serrations and/or Porous Material," 19th AIAA/CEAS Aeroacoustics Conference, 2013.

${ }^{10}$ Skillen, A., Revell, A., Pinelli, A., Piomelli, U., and Favier, J., "Flow over a Wing with Leading-Edge Undulations," AIAA Journal, Vol. 53, No. 2, 2015, pp. 464-472.

${ }^{11}$ Staubs, J. K., "Real Airfoil Effects on Leading Edge Noise," Ph.D. Dissertation, Faculty of the Virginia Polytechnic Institute, Blacksburg, USA, May 2008.

${ }^{12}$ Biedermann, T., "Aerofoil Noise Subjected to Leading Edge Serration," Master Dissertation, Institute of Sound and Vibration Engineering ISAVE, Düsseldorf, September 2015.

${ }^{13}$ Biedermann, T., Chong, T. P., and Kameier, F., "Statistical-empirical modelling of aerofoil noise subjected to leading edge serrations and aerodynamic identification of noise reduction mechanisms," 22nd AIAA/CEAS Aeroacoustics Conference, 2016.

${ }^{14}$ Biedermann, T. M., Chong, T. P., Kameier, F., and Paschereit, C. O., "Statistical-Empirical Modelling of Airfoil Noise Subjected toLeading Edge Serrations," AIAA Journal, 2017.

${ }^{15}$ Reich, M., Adam, M., and Lambach, S., "Comparison of different Methods for Approximating Models of Energy Supply Systems and Polyoptimising the Systems-Structure and Components-Dimension," ECOS 2017 - The 30th International Conference on Efficiency, Cost, Optimization and Environmental Impact of Energy Systems, 2017.

${ }^{16}$ Chaitanya, P., Narayanan, S., Joseph, P., and Kim, J. W., "Leading edge serration geometries for significantly enhanced leading edge noise reductions," 22nd AIAA/CEAS Aeroacoustics Conference, 2016.

${ }^{17} \mathrm{Kim}$, J. W., Haeri, S., and Joseph, P. F., "On the reduction of aerofoil-turbulence interaction noise associated with wavy leading edges," Journal of Fluid Mechanics, Vol. 792, 2016, pp. 526-552.

${ }^{18}$ Turner, J., and Kim, J. W., "Towards Understanding Aerofoils with Wavy Leading Edges Interacting with Vortical Disturbances," 22st AIAA/CEAS Aeroacoustics Conference, 2016.

${ }^{19}$ Turner, J., Kim, J. W., Paruchuri, C. C., and Joseph, P., "Towards Understanding Aerofoils with Dual-Frequency Wavy Leading Edges Interacting with Vortical Disturbances," 22st AIAA/CEAS Aeroacoustics Conference, 2016.

${ }^{20}$ Turner, J. M., and Kim, J. W., "Aeroacoustic source mechanisms of a wavy leading edge undergoing vortical disturbances," Journal of Fluid Mechanics, Vol. 811, 2017, pp. 582-611.

${ }^{21}$ Hansen, K. L., Kelso, R. M., and Dally, B. B., "Performance Variations of Leading-Edge Tubercles for Distinct Airfoil Profiles," AIAA Journal, Vol. 49, No. 1, 2011, pp. 185-194.

${ }^{22}$ Johari, H., Henoch, C. W., Custodio, D., and Levshin, A., "Effects of Leading-Edge Protuberances on Airfoil Performance," AIAA Journal, Vol. 45, No. 11, 2007, pp. 2634-2642.

${ }^{23}$ Yoon, H. S., Hung, P. A., Jung, J. H., and Kim, M. C., "Effect of the wavy leading edge on hydrodynamic characteristics for flow around low aspect ratio wing," Computers \& Fluids, Vol. 49, No. 1, 2011, pp. 276-289.

${ }^{24}$ Drela, M., and Youngren, H., xfoil, Ver. 6.99, 2013.

${ }^{25}$ Hansen, K. L., Kelso, R. M., and Dally, B. B., "The Effect of Leading Edge Tubercle Geometry on the Performance of Different Airfoils," 7th World Conference on Experimental Heat Transfer, Fluid Mechanics and Thermodynamics, 2009.

${ }^{26}$ Egorov, Y., Menter, F. R., Lechner, R., and Cokljat, D., "The Scale-Adaptive Simulation Method for Unsteady Turbulent

Flow Predictions. Part 2: Application to Complex Flows," Flow, Turbulence and Combustion, Vol. 85, No. 1, 2010, pp. $139-165$.

${ }^{27}$ Menter, F., and Egorov, Y., "Zonal LES in CFX-14.5 ( $\beta$ Feature)," 2016. 